\title{
Degenerative and regenerative changes in the trochlear nerve of goldfish
}

\author{
STEVEN S. SCHERER and STEPHEN S. EASTER JR \\ Division of Biological Sciences, The University of Michigan, Ann Arbor, MI 48109, USA
}

Received 23 August and 15 September 1983; revised 22 February 1984; accepted 5 March 1984

\section{Summary}

The features of unlesioned and lesioned trochlear nerves of goldfish have been examined electron microscopically. Lesioned nerves were studied between 1 and 107 days after cutting or crushing the nerve.

1. Unlesioned nerves contained, on average, 77 myelinated axons and 19 unmyelinated axons. The latter were found in 1-2 fascicles per nerve. A basal lamina surrounded each myelinated axon and fascicle of unmyelinated axons. The numbers of myelinated axons, fascicles of unmyelinated axons and basal laminae varied by less than $5 \%$ over the intraorbital extramuscular segment of the nerve.

2. Following interruption of the nerve, by either cutting or crushing, all of the axons and their myelin sheaths began to degenerate by 4 days in the distal nerve-stump. Both abnormally electron-dense and electron-lucent axons were observed. Both Schwann cells and macrophages appeared to phagocytose the myelin sheaths.

3. Following a lesion, the Schwann cells and their basal laminae persisted in the distal nervestump. In crushed nerves, the basal laminae surrounding myelinated axons formed $97 \%$, on average, of the Schwann tubes in the distal stump. The perimeters of the basal laminae were of similar size to those in the proximal stump, at least for the first 8 days after crush.

4. In crushed nerves, single myelinated axons in the proximal nerve-stump gave rise to multiple sprouts, some of which reached the site of crush by 2 days, the distal stump by 4 days and the superior oblique muscle by 8 days. The regeneration of the unmyelinated axons was not examined.

5. In both crushed and transected nerves, nearly all of the sprouts in the proximal and distal stumps were found within the basal laminae of Schwann cells, even though the sprouts were disorganized in the transected region where there were no basal laminae. The growth cones of the regenerating axons were always found apposed to the inner surface of the basal laminae, which may have provided an adhesive substrate that directed their growth.

6. Terminal sprouts from the ends of myelinated axons in the proximal stump accounted for the majority of the regenerating axons in the distal stump, as only a few collateral sprouts were found in the proximal stump, and only a small amount of axonal branching was found within the distal stump itself.

7. The largest axons in the distal stump were remyelinated first, and the number of remyelinated axons increased progressively between 8 and 31 days after crush, at which time there were about twice as many as in unlesioned nerves. The number of remyelinated axons remained constant at 
least until 107 days, the longest time considered, and none was observed to degenerate, whereas some axons that were not remyelinated appeared to degenerate.

8. Although each basal lamina in the distal stump often surrounded several regenerating axons during the first 2 weeks post-lesion, each remyelinated axon became individually surrounded by a basal lamina, collagen fibres and extracellular space between 13 and 107 days, thereby increasing the number of basal laminae in the distal stump.

9. Regenerated axonal terminals in the superior oblique were first observed 8 days after crush. The number of synapses increased progressively between 8 and 107 days, at which time they were as numerous as in unlesioned animals.

\section{Introduction}

Although axonal regeneration has been extensively studied in mammalian peripheral nerves (Ramón y Cajal, 1928; Guth, 1956), there have been only a few studies in anamniotic vertebrates. This is surprising, since it is widely believed that regenerating axons can selectively reinnervate their appropriate peripheral targets in teleosts and urodeles (Mark, 1965; Sperry \& Arora, 1965; Grimm, 1971; Stephenson, 1979), but not in mammals (reviewed by Sperry, 1945; Gaze, 1970). We have therefore studied electron microscopically both qualitative and quantitative aspects of axonal regeneration in the trochlear nerve of goldfish. We have emphasized the basal laminae of Schwann cells because after a lesion they become the so-called Schwann, endoneurial or neurilemmal tubes in the distal nerve-stump (Thomas, 1964), within which almost all of the regenerating axons are found.

The trochlear nerve was chosen for several reasons: (1) It is believed to be exclusively motor and to innervate the superior oblique muscle exclusively (Luiten \& Dijkstra-de Vlieger, 1978; Easter, 1979). (2) Both the nerve and the muscle are small enough to allow entire transverse sections to be viewed on a single electron microscopic grid. (3) Unlesioned nerves consist predominantly of myelinated axons, the number of which, about 80 (Easter, 1979), is low enough that all axons can be conveniently counted. (4) The number of axons is nearly constant throughout the length of unlesioned nerves (Easter, 1979) so that, for each nerve, the number of regenerating axons in the distal nerve-stump can be compared to the number in the proximal stump.

\section{Methods}

Preparation of tissues

Commercially obtained, common goldfish (Carassius auratus), between 7 and $9 \mathrm{~cm}$ standard length, were anaesthetized by immersion in $0.1 \%$ aqueous tricaine methane sulphonate. The conjunctiva and connective tissue of the dorsal orbit were separated on a dissecting microscope to expose the intraorbital segment (about $5 \mathrm{~mm}$ long) of the left trochlear nerve. The nerve was either crushed with fine forceps or cut, about $1 \mathrm{~mm}$ from the medial edge of the superior oblique muscle (Fig. 1). As the surgery produced only a narrow wound, no additional measures were taken to close it. Animals were returned to home tanks, which were maintained between 18 and $23{ }^{\circ} \mathrm{C}$, until sacrifice.

At $1,2,3,4,8,13,31,64$ or 107 days post-lesion, animals were reanaesthetized, decapitated and 
the orbit and cranium opened to expose their contents to fixative at room temperature. The fixative contained 3.2\% glutaraldehyde, $3 \%$ formaldehyde (freshly prepared from paraformaldehyde), $1 \%$ dimethylsulphoxide, $0.1 \%$ picric acid, $0.001 \mathrm{M} \mathrm{CaCl}_{2}$, in $0.01 \mathrm{M} \mathrm{Na}$ cacodylate buffer (pH 7.2-7.4). After $1 \mathrm{~h}$, each trochlear nerve was dissected out in continuity with the superior oblique muscle and put in fresh fixative for an additional hour, washed in several changes of buffer ( $3 \%$ sucrose, $0.001 \mathrm{M} \mathrm{CaCl}_{2}$, in $0.10 \mathrm{M} \mathrm{Na}$ cacodylate buffer), and postfixed in similarly buffered $2 \% \mathrm{OsO}_{4}$ for several hours at room temperature. After block-staining in 0.5\% uranyl acetate (Karnovsky, 1967) or 1\% tannic acid (TA) (Simionescu \& Simionescu, 1976), the tissue was dehydrated in a graded series of ethanols, cleared in propylene oxide and embeded in plastic (either Araldite or Epon-Araldite). Several nerves were not block-stained, but were instead immersed in 1\% phosphotungstic acid (PTA) in absolute ethanol for several hours during dehydration (Thomas, 1963).

Between 1 and 13 days after crush, the lesion was identified as a pale indentation in embedded nerves. Between 31 and 107 days, the histological appearance of the nerve and its proximity to the superior oblique muscle served to identify the proximal and distal stumps. Nerves were sectioned both longitudinally, through the lesion, and transversely, at selected sites in the proximal stump, the distal stump and the site of the lesion. For quantitative analysis, each nerve was sectioned transversely both $2-4 \mathrm{~mm}$ proximal to and $0.3-0.6 \mathrm{~mm}$ distal to the site of the lesion. Semithin sections ( $1 \mu \mathrm{m}$ thick) were stained with toluidine blue ( $1 \%$ in $1 \% \mathrm{Na}$ borate) for light microscopy. Thin sections (silver to gold interference colours) were mounted on Formvar-coated one-hole grids, and stained with lead citrate (Reynolds, 1963) and saturated aqueous uranyl acetate. No corrections were made for histological shrinkage or compression due to sectioning.

\section{Quantitative analysis}

For a complete quantitative analysis of axons, it was necessary to classify them as either remyelinated, intact myelinated, unmyelinated or non-myelinated. An axon that was at least partially surrounded by compact myelin was considered to be remyelinated if the myelin sheath was thinner than that found around similarly sized, unlesioned myelinated axons, which we called 'intact'. The unmyelinated axons of unlesioned nerves (Easter, 1979) were distinguished from non-myelinated axons: the regenerating sprouts that were found only in lesioned nerves. These definitions extend those of Cook et al. (1974), who defined non-myelinated axons in the developing feline optic nerve as 'immature axons that eventually become myelinated' as distinct from 'unmyelinated axons, which are never myelinated'. To extend the definition of non-myelinated axons to include the regenerating sprouts described below was appropriate, since they were initially immature and the majority were eventually remyelinated.

Non-myelinated axons were distinguished from Schwann cell processes by their round to oval shape and electron-lucent cytoplasm, which contained microtubules and neurofilaments, but which lacked ribosomes and rough endoplasmic reticulum. Although Schwann cell processes sometimes appeared similar to axons, even containing $10 \mathrm{~nm}$ filaments and microtubules, Schwann cell filaments, unlike neurofilaments, were usually tightly packed and were not interconnected by prominent wispy material (Fig. 22, inset; see also Politis \& Spencer, 1981; Tohyama et al., 1983). That these criteria were adequate to distinguish non-myelinated axons from Schwann cell processes was directly tested. In two animals, the intracranial portion of the trochlear nerve was removed about $5 \mathrm{~mm}$ central to the site where it had been previously crushed ( 8 or 10 days before) to cause the degeneration of the axons that had begun to regenerate after the crush. The animals were sacrificed after 2 days, which was enough time to cause Wallerian degeneration in other animals, and the trochlear nerves were examined electron microscopically. We predicted that if the above criteria adequately distinguished non-myelinated axons from Schwann cell processes, then all of the non-myelinated axons distal to the site of crush should have started to degenerate. In confirmation of this prediction, we found many Schwann cell processes, but only a 
few non-myelinated axons, that had a well-preserved ultrastructure; the vast majority of the non-myelinated axons appeared similar to other degenerating axons (see below).

For quantitative analysis, complete protomosaics of entire transverse sections were constructed from overlapping electron micrographs ( $\times 8000-9100)$. Well-myelinated axons and the basal laminae of Schwann cells were counted directly from the photomosaic; thinly myelinated, unmyelinated and non-myelinated axons were counted by re-examining, at higher magnifications, the same grid that was the subject of the photomosaic. To demonstrate that this method was reproducible, it was repeated on one section that had been counted more than a month before, from a nerve 8 days after crush, the time at which the number of non-myelinated axons was maximal. The numbers of basal laminae $(n=87)$ and remyelinated axons $(n=2)$ were exactly the same, and the number of non-myelinated axons differed by only $3 \%(273 \mathrm{v}$. 266). The perimeters of the basal laminae of Schwann cells were measured from the photomosaics using a digitizing tablet (Zeiss MOP-3).

The number of myelinated axons was also determined light microscopically by counting the number of camera lucida tracings of the myelin sheaths from single transverse sections. Repeated counts of the same section were within $3 \%$ of each other.

Entire transverse sections through the belly of the superior oblique muscle were examined by viewing them electron microscopically in a series of parallel passes, in which about one-third of the previous field was included in that of the next pass. All of the synapses, defined as an axonal process containing clear vesicles directly apposed to the basal lamina of a muscle cell, were counted. Repeated counts of the same section were within $15 \%$ of one another.

\section{Horseradish peroxidase (HRP)}

In one animal, a piece of HRP-impregnated Gelfoam (Upjohn) was placed next to the freshly cut distal stump of each trochlear nerve; the left one had been crushed more distally 33 days before and the right one had not been previously lesioned. After $18 \mathrm{~h}$, the distal stumps and attached muscles were removed, reacted with $o$-dianisidine (Easter et al., 1981), cleared and examined as wholemounts. An inferior oblique nerve, a control for endogenous peroxidase activity, showed no staining.

\section{Results}

STRUCTURE OF THE UNLESIONED NERVE

\section{Gross anatomy}

We have confirmed and extended previous descriptions of the trochlear nerve in goldfish (Mark \& Marotte, 1972; Easter, 1979). As drawn in Fig. 1, the trochlear nerve (IV) left the brain at the junction of the midbrain and cerebellum (c), dorsal to the root of the trigeminal nerve (V), and joined the supraorbital trunk (st), a collection of axons from the trigeminal, facial and anterior lateral line nerves (Herrick, 1899; Luiten, 1979). The trochlear nerve and supraorbital trunk passed rostrad beneath the tectum $(t)$ to enter the dorsocaudal quadrant of the orbit through a common foramen. The two usually separated where they entered the orbit; the trochlear nerve alone continued rostrad to enter the belly of the superior oblique muscle (so), whereas the supraorbital trunk remained dorsal where it branched to innervate the orbit. Occasionally, the two remained together to the point where the trochlear nerve branched to enter the superior 


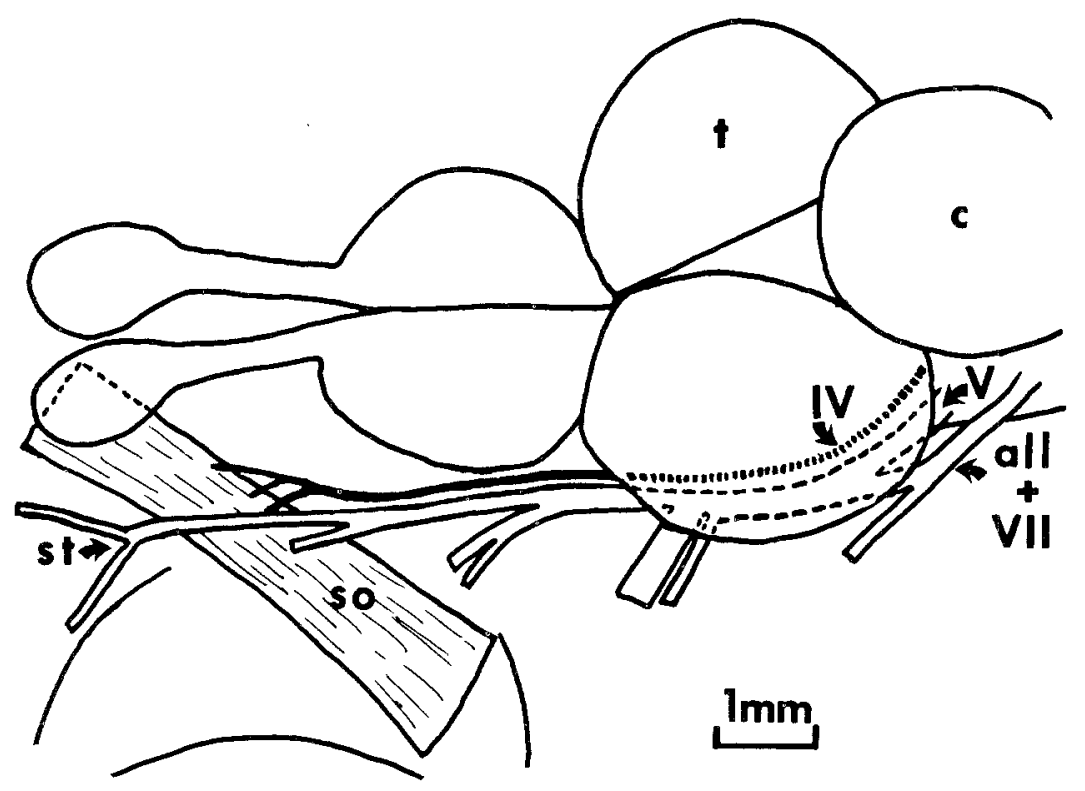

Fig. 1. Diagram of goldfish brain as seen from a dorsal and slightly lateral view. Only the trochlear (IV), trigeminal (V), facial (VII), and anterior lateral line (all) nerves are shown. c, Cerebellum; $t$, tectum; so, superior oblique muscle; st, supraorbital trunk.

oblique muscle; the supraorbital trunk continued rostrad over the dorsal surface of the muscle and did not enter it.

Several animals were excluded from this study because the trochlear nerve and supraorbital trunk were found to be anastomosed intraorbitally, so that a lesion could not have been confined to the trochlear nerve. These cases were usually found during the initial surgery, but some cases were detected only after histological examination of the trochlear nerve.

\section{Microscopic anatomy}

We examined the connective tissue of both the intraorbital and intracranial segments of the trochlear nerve. Three divisions - epineurium, perineurium and endoneurium were identified according to previous electron microscopic descriptions of mammalian peripheral nerves (reviewed by Thomas \& Olsson, 1975).

The outermost layer, the epineurium, was the most superficial connective tissue. It was composed of fibroblasts and bundles of collagen fibres, and was continuous with and identical to the adjacent connective tissue of the orbit. An epineurium was found in the intraorbital, but not the intracranial, segment of the nerve.

The perineurium was the multi-layered, cellular sheath that surrounded the external surface of the nerve and its branches (Figs. 2,5). It consisted of several circumferential layers of flattened cells that were joined by tight junctions and desmosomes (Fig. 5). 
Bundles of collagen fibres and finer filaments (Thomas, 1963), generally orientated longitudinally with respect to the nerve, were observed between adjacent layers (Fig. 5). The intracranial and intraorbital segments of the perineurium differed from one another in several respects. There were fewer cellular layers intracranially than intraorbitally (1-4 $v .4-8$ ) and there was less collagen between the layers intracranially. Numerous caveolae were present intraorbitally, but not intracranially. Although the basal laminae of other cell types were well stained (Fig. 5), only a few patches of perineurial basal lamina were present intraorbitally, and no basal lamina was found intracranially, even after appropriate treatments with tannic or phosphotungstic acid. The absence of a basal lamina was surprising, as it is well developed on mammalian and amphibian perineurial cells (Akert et al., 1976).

The endoneurium, the connective tissue enclosed by the perineurium, was present both intracranially and intraorbitally (Fig. 2). An endoneurial blood vessel was noted in about one-half of the intraorbital segments, but never in the intracranial segments. Schwann cells, collagen and fibroblasts made up the bulk of the endoneurium, which also contained a smaller number of mast cells, macrophages and capillary endothelial cells.

Schwann cells were identified by their myelin or their association with unmyelinated axons, and by their prominent basal lamina (Figs. 4, 5). Their moderately electron-dense cytoplasm, mainly found around the nucleus, contained rough endoplasmic reticulum, Golgi complexes, mitochondria and primary lysosomes. In addition, the cytoplasm around the inner and outer periphery of the myelin sheath and in the processes associated with unmyelinated axons, contained microtubules and $10 \mathrm{~nm}$ filaments that were longitudinally orientated with respect to the axons.

Most of the collagen fibres surrounded the basal laminae of Schwann cells, forming a thick layer orientated longitudinally with respect to the axons (Figs. 4, 5; see also Thomas, 1963). Intraorbitally, the collagen fibres were numerous and evenly arranged around the Schwann cells; intracranially, however, they were sparse and unevenly distributed.

Endoneurial fibroblasts had a similar ultrastructure to perineurial cells, except that they were more branched and completely lacked a basal lamina. Their long, thin

Figs. 2-7. Normal features of the trochlear nerve. Although Figs. 3-7 are derived from the proximal stumps of lesioned nerves, they are fully representative of features found in unlesioned nerves. Scale bars: $10 \mu \mathrm{m}$ in Fig. 2; $1 \mu \mathrm{m}$ in Figs. 3-7.

Fig. 2. A transverse section of the intraorbital portion of an unlesioned nerve. The perineurium (arrowheads) surrounds 83 myelinated and 12 unmyelinated axons. Arrows point to some of the endoneurial fibroblasts.

Fig. 3. An endoneurial mast cell. Proximal stump, 31 days after crush.

Fig. 4. Collagen fibres (c) and a basal lamina (arrows) surround a single Schwann cell that is associated with 11 unmyelinated axons $(\star)$. Proximal stump, 31 days after crush. 

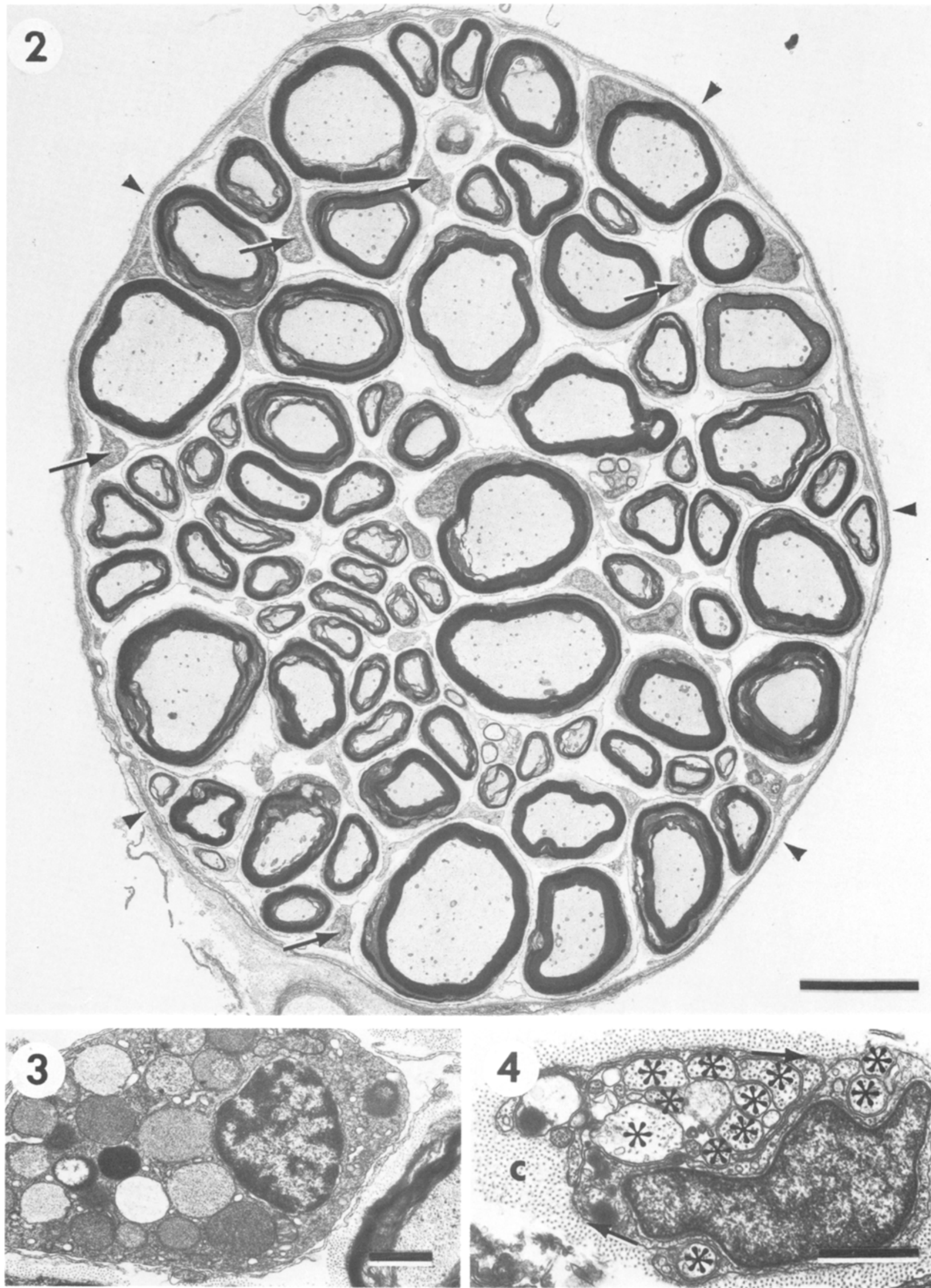

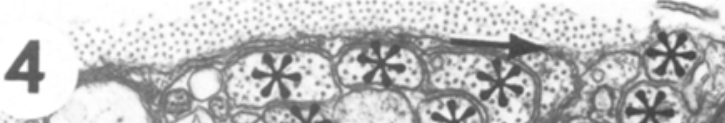

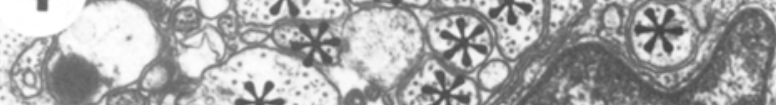

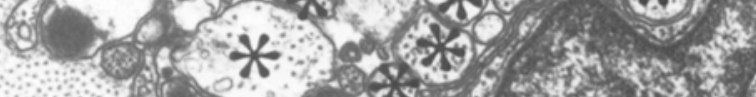

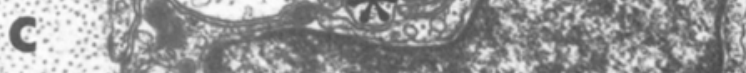

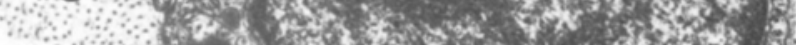

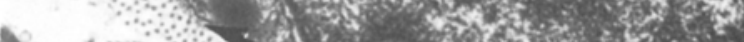
thes the d. (1. 
processes were connected to each other by desmosomes and tight junctions, forming a mesh-like pattern around the axons that extended throughout the endoneurium to the inner surface of the perineurium (Fig. 2).

Mast cells were characterized by numerous membrane-bound vesicles, which averaged about $2 \mu \mathrm{m}$ in diameter, contained finely granular material of variable electron density (Fig. 3), and were stained dark blue by toluidine blue applied to semithin sections. They were found within and adjacent to the trochlear nerve and superior oblique muscle; similar cells have also been reported in the optic nerve (Murray, 1982). Although the existence of mast cells in teleosts is debated (Ellis, 1977), they were remarkably similar to mammalian mast cells (Bloom \& Fawcett, 1975), which are found in peripheral nerves (Thomas \& Olsson, 1975).

Macrophages lacked basal laminae and were characterized by filopodia and an electron-dense cytoplasm, which contained small (average diameter: $0.3 \mu \mathrm{m}$ ), membrane-bound, electron-lucent vesicles, Golgi complexes, rough endoplasmic reticulum and primary lysosomes. Their identity as macrophages is supported by their ultrastructural similarity to haematogenous macrophages of other teleosts (Ferguson, 1976; Cannon et al., 1980; Barber et al., 1981); similar cells were also observed within the lumina of blood vessels.

There were myelinated and unmyelinated axons in the intraorbital segment of unlesioned nerves. The axoplasm of myelinated axons was electron-lucent and contained abundant neurofilaments as well as bundles of microtubules, mitochondria

Fig. 5. A transverse section of 8 perineurial processes $(\star)$, two of which are joined by a desmosome (arrow). A myelin sheath $(\mathrm{m})$ is surrounded by a basal lamina (arrowheads) and collagen fibres (c), which are also found between adjacent perineurial cells. Proximal stump, 31 days after crush, tannic acid (TA) post-fixation.

Fig. 6. Four myelinated axons ( $\star$ ) of the trochlear nerve (below arrows) are adjacent to the smaller ones of the supraorbital trunk (above) without any intervening cellular processes. Proximal stump, 31 days after crush, TA post-fixation.

Fig. 7. An intact myelinated axon; compare with Figs. 8, 9. A myelin sheath (m) surrounds the axon, which mostly contains neurofilaments (f) and microtubules (arrows) and the surrounding wispy material. Part of the axolemma is located between the arrowheads. Proximal stump, 8 days after transection.

Fig. 8. A degenerating myelinated axon. The myelin sheath $(\mathrm{m})$ is split, but otherwise intact. An intact axolemma (arrowheads) surrounds neurofilaments $(f)$ and microtubules (arrows), both of which persist in an abnormally electron-dense cytoplasm. Distal stump, 2 days after crush. Scale bar: $1 \mu \mathrm{m}$.

Fig. 9. A degenerating myelinated axon. An intact myelin sheath (m) surrounds the flocculent, electron-lucent cytoplasm, but no axolemma is visible. Distal stump, 2 days after crush. Scale bar: $1 \mu \mathrm{m}$.

Fig. 10. A degenerating myelinated axon. The Schwann cell contains prominent Golgi complexes (arrowheads) and a myelin ellipsoid $(\mathrm{m})$ that surrounds an electron-dense axon (arrow). Distal stump, 2 days after crush. Scale bar: $1 \mu \mathrm{m}$. 

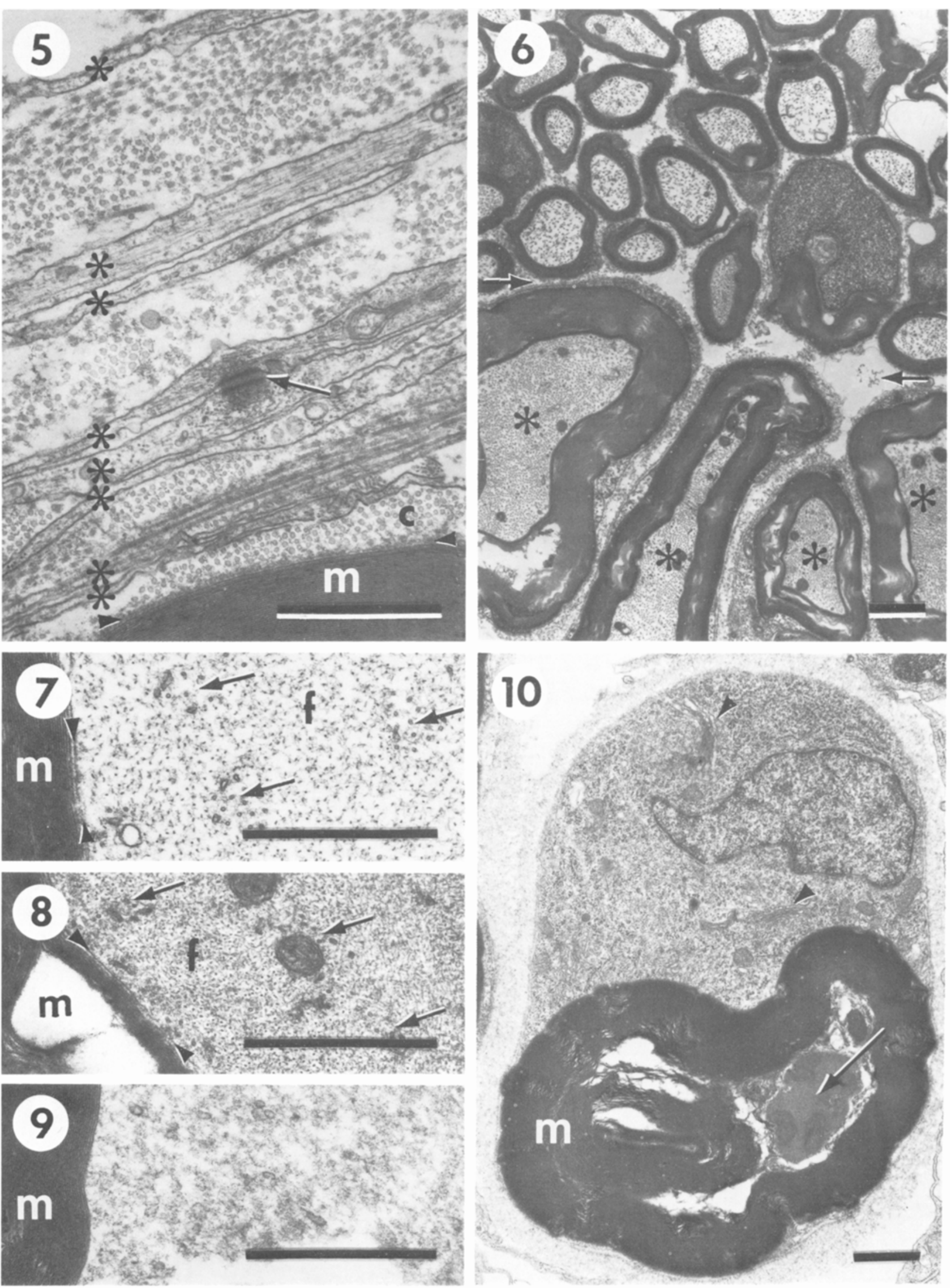
and smooth endoplasmic reticulum, all of which were longitudinally orientated (Fig. 7). The unmyelinated axons were always found in fascicles, each of which contained up to 20 axons and 2 Schwann cells. Schwann cell processes surrounded the axons individually or in small groups, and all of the axons within a fascicle were usually found within the same basal lamina (Fig. 4). Unmyelinated axons were similiar ultrastructurally to myelinated axons but they were smaller $(0.1-1 \mu \mathrm{m} v, 1-15 \mu \mathrm{m}$ in diameter; Easter, 1979) and microtubules were more common than neurofilaments (Fig. 4).

To investigate the possibility of axonal branching within the nerve trunk, the intraorbital segments of 3 unlesioned nerves were examined at the two sites (about $4 \mathrm{~mm}$ apart) that corresponded to the sites sampled in lesioned nerves. The number of myelinated axons at these two sites differed by $0(73,73), 1(81,82)$ and $4(76,80)$. The number of fascicles of unmyelinated axons was invariant (1,2 and 2). This analysis shows that in the trochlear nerve, axonal branching was insignificant (Easter, 1979), and, in addition, that $98 \%$ of the basal laminae, on average, surrounded myelinated axons.

We investigated the possibility that the unmyelinated axons in the trochlear nerve were derived from the supraorbital trunk. The supraorbital trunk contained hundreds of tightly packed, small axons, both myelinated and unmyelinated. Axons from the supraorbital trunk could have joined the trochlear nerve where the two nerves anastomosed within the foramen, as electron microscopic examination of several anastomoses demonstrated that their axons were not separated by either perineurial or endoneurial cells (Fig. 6). Electron microscopic examination of 4 trochlear nerves, both central and peripheral to an anastomosis, demonstrated that all of them had unmyelinated axons peripherally, whereas only 1 of 4 did centrally. Thus, it seems likely that the unmyelinated axons were not trochlear motor axons, but were instead derived from the supraorbital trunk. In addition, a few myelinated axons from the supraorbital trunk may have also joined each trochlear nerve via an anastomosis.

\section{DEGENERATIVE CHANGES IN THE NERVE}

Degeneration in the distal stump

We examined axonal degeneration in the trochlear nerve to avoid the potential confusion between regenerating and persisting axotomized axons, which have been described in both invertebrates (Bittner \& Johnson, 1974; Elliot \& Muller, 1981) and vertebrates (Kruger \& Maxwell, 1969; Matsumoto \& Scalia, 1981). Since degenerating unmyelinated axons could not be unambiguously identified, the following comments are restricted to degenerating myelinated axons, which were the most numerous and could often be identified by the presence of myelin debris. Although the quantitative analysis was restricted to crushed nerves, degeneration in transected nerves did not differ in any obvious way.

The appearance of axons in the distal stump was variable. Between 2 and 4 days post-lesion, only a few of the hundreds of axons examined appeared intact; the rest were either abnormally electron-dense or electron-lucent. Electron-dense axons had a dark 
and finely granular cytoplasm that usually contained microtubules and neurofilaments (Fig. 8). Unlike electron-lucent axons, the axolemma of electron-dense axons was usually preserved. Electron-lucent axons had a flocculent cytoplasm that did not contain microtubules or neurofilaments (Fig. 9). Both kinds of axons occasionally contained groups of mitochondria that were often swollen as described by Webster (1962). Since electron-dense axons appeared to be better preserved than electron-lucent ones, intact axons may have degenerated into electron-lucent ones via an intermediate, electron-dense stage. Neither electron-dense nor electron-lucent axons were found in the distal stump at 13 days.

By 4 days post-lesion, most myelin sheaths were segmented into units, tens of micrometres in length in longitudinal sections, termed ellipsoids (Ohmi, 1961), which were often collapsed and complexly folded within the Schwann cells (Fig. 10). Schwann cells also contained smaller fragments of electron-dense, lamellar material, presumably myelin debris, and lipid droplets, both of which were probably derived from the degradation of ellipsoids (Rawlins et al., 1972). The number of ellipsoids steadily declined between 2 and 13 days, and they were not observed at 31 days, although myelin debris and lipid droplets were occasionally found. Thus, both the axon and its myelin sheath began to degenerate during the first week, but the degeneration of the myelin sheath was prolonged relative to that of the axon.

During the first month post-lesion, macrophages, often containing myelin debris and lipid droplets, were observed inside, within and outside the layers of the perineurium. We found macrophages within the basal laminae of degenerating myelinated axons, and in several cases, actually crossing them (Fig. 11). In the endoneurial space surrounding the basal laminae, there were many macrophages (Fig. 22), but free myelin debris was not observed. There were macrophages between the layers of the perineurium, and we observed several passing between adjacent perineurial cells (Fig. 12) in a manner reminiscent of emigrating cells in blood vessels. The epineurium and adjacent connective tissue also contained many macrophages that were frequently disposed around, and sometimes within, blood vessels. From the distribution of macrophages containing myelin debris, it seems likely that macrophages invaded the basal laminae of degenerating axons and phagocytosed myelin, then left the nerve via the perineurium to enter adjacent blood vessels.

\section{The formation of Schwann tubes}

During the first 2 weeks post-lesion, Schwann cells were identified by their relationship to regenerating axons and by their basal lamina (Figs. 10, 13, 18, 24). Compared to Schwann cells in unlesioned nerves, they possessed more cytoplasm (Fig. 10), which contained myelin debris, lipid droplets and an increased amount of ribosomal rosettes, rough endoplasmic reticulum, Golgi complexes and $10 \mathrm{~nm}$ filaments (Figs. 10, 18-24), in addition to the normal features already described. Their morphology also changed: there were numerous Schwann cell processes adjacent to basal laminae, often surrounding regenerating axons (Figs. 21-24). The presence of mitotic figures (Fig. 13) 
and an increased number of Schwann cells indicated that they were proliferating during this period.

Thomas (1964) redefined the Schwann tube as the contents of the basal laminae of Schwann cells which, along with the surrounding endoneurial collagen, persist in the distal stump after a lesion. During the first 2 weeks after crush, Schwann tubes surrounded myelin debris (Fig. 11), Schwann cells (Figs. 10, 13, 18-24), macrophages (Fig. 11), regenerating axons (Figs. 13, 16-24) and empty space (Fig. 14). Since $98 \%$ of the basal laminae surrounded myelinated axons in unlesioned nerves and the number of both of these varied insignificantly over the intraorbital segment, we could infer the following. (1) All of the basal laminae in the distal stumps were preserved during the first 2 weeks after crush because the numbers of basal laminae in the proximal and distal stumps were equal (Fig. 37d). (2) Before the basal laminae in the distal stumps became subdivided ( 2 weeks after crush, see below), $97 \%$ of them, on average, had originally surrounded myelinated axons because $97 \%$ of the basal laminae surrounded myelinated axons (mean $=81.3)$ in the corresponding proximal stumps $(n=31)$.

We also examined the shapes and sizes of the basal laminae of Schwann cells in the distal stump. Between 2 and 13 days after crush, they were mostly round to oval in shape (Figs. 10, 13, 22-24), like those around unlesioned myelinated axons. Although a few basal laminae had irregular shapes (Fig. 14), they were rarely corrugated and separated from their Schwann cells as described in lesioned mammalian peripheral nerves (Thomas, 1964; Morris et al., 1972). We measured the perimeters of the basal laminae, and compared the distributions of the perimeters between the distal and proximal stumps for each nerve. Although there were no significant differences between the two stumps in unlesioned nerves, at 4 and 8 days after crush the perimeters in some of the distal stumps were significantly smaller (Table 1). The distributions of the perimeters in 4 of the 14 nerves listed in Table 1 are shown graphically in Fig. 15.

Fig. 11. An endoneurial macrophage containing myelin debris (arrow) and lying adjacent to a Schwann tube $(\star)$ that also contains myelin debris (d). Distal stump, 2 days after crush. Scale bar: $1 \mu \mathrm{m}$. Inset: in an adjacent section, the process of the macrophage (between arrowheads) enters the Schwann tube through the basal lamina. Scale bar: $1 \mu \mathrm{m}$.

Fig. 12. A macrophage that lies between two layers of the perineurium ( $\star$ ); its process (arrow) passes between two perineurial cells of the same layer. Proximal stump, 8 days after transection. Scale bar: $1 \mu \mathrm{m}$. Inset: in an adjacent section, the two perineurial cells are contiguous, and appear to separate the process in two. Note the caveolae (arrows) in the perineurial cell and the finely. granular cytoplasm in the process of the macrophage Scale bar: $1 \mu \mathrm{m}$.

Fig. 13. A Schwann tube that contains a regenerating axon $(\star)$, a Schwann cell containing condensed chromatin (double arrowhead) and 2 Schwann cell processes (outlined by arrowheads). Distal stump, 4 days after crush, phosphotungstic acid (PTA) post-fixation. Scale bar: $1 \mu \mathrm{m}$.

Fig. 14. An empty Schwann tube ( $\star$ ). Collagen fibres (c) surround a basal lamina (arrows) that does not contain a cellular profile. Crush site, 8 days after crush, TA post-fixation. Scale bar: $1 \mu \mathrm{m}$. 

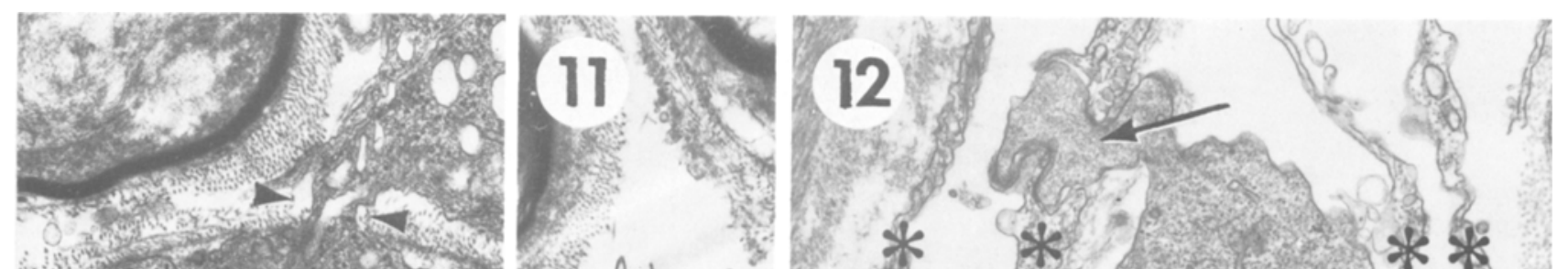

git 5 ?

S60 203

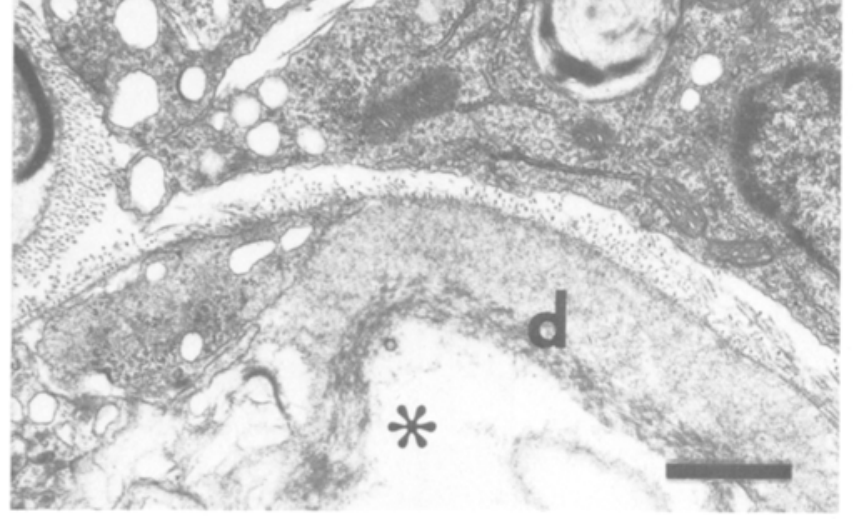

* 30

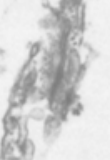

8

oy esters
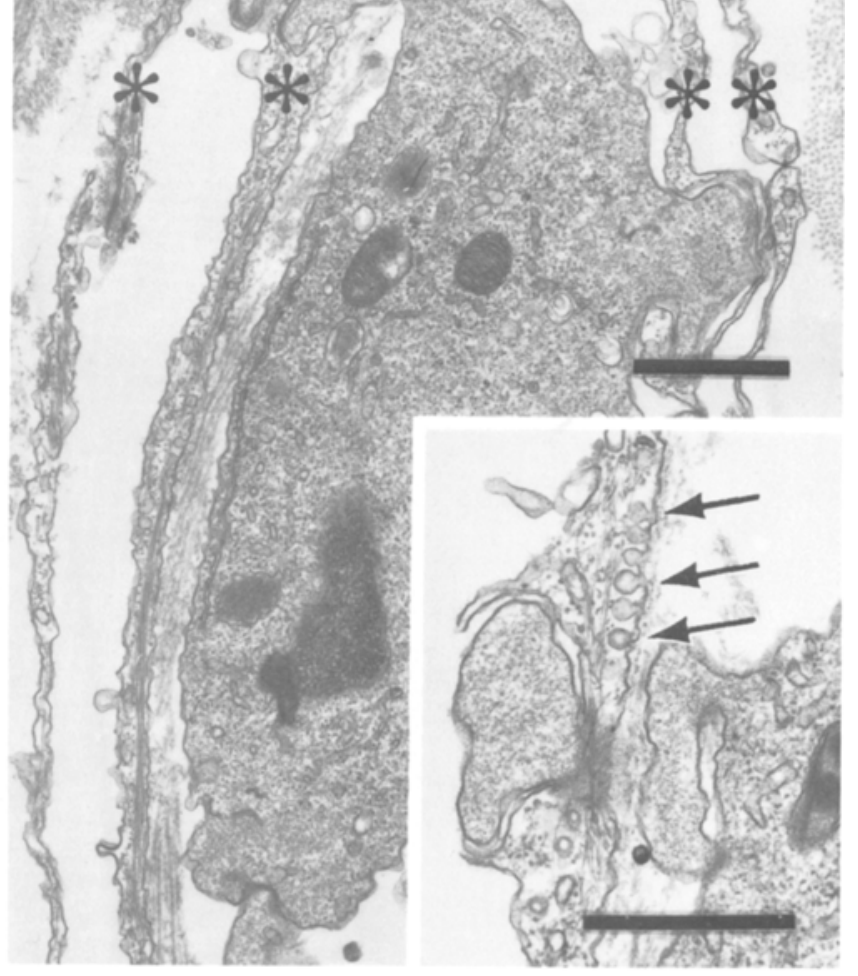

13

7. 14

1

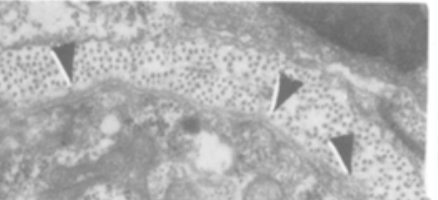

14 inton

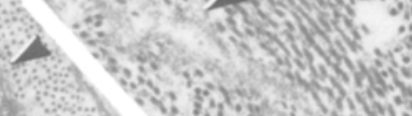

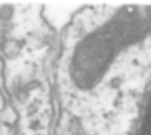
$x^{2}\left(x^{2}\right.$ $60^{*}: 4$ $4 y^{2}$ :

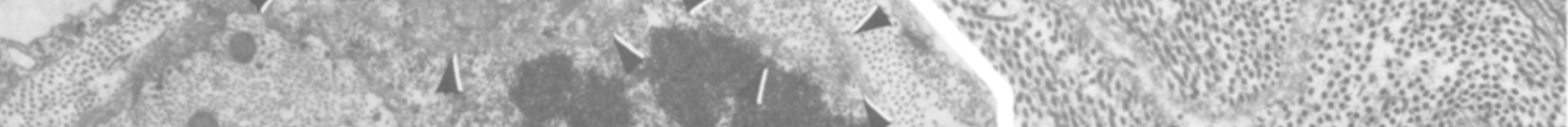
F. 

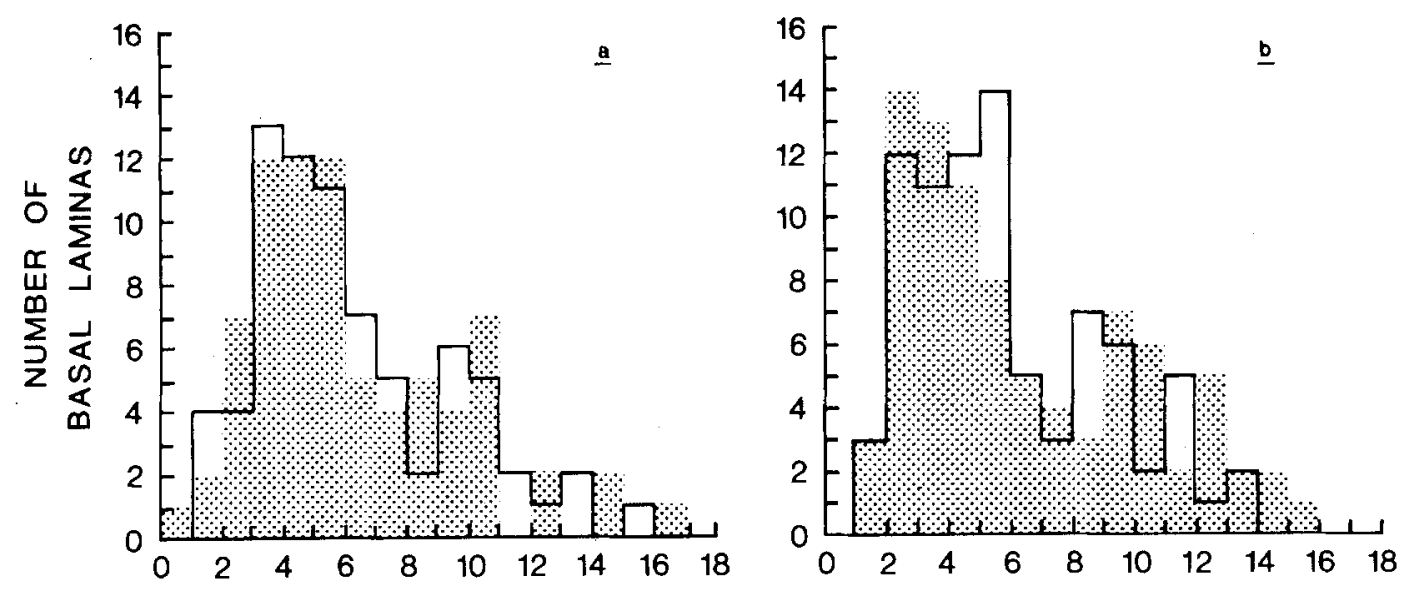

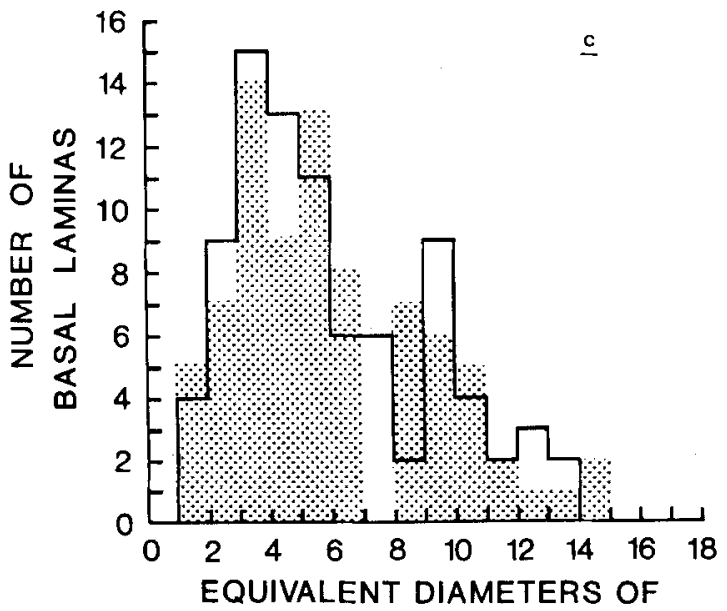

BASAL LAMINAS $(\mu \mathrm{m})$

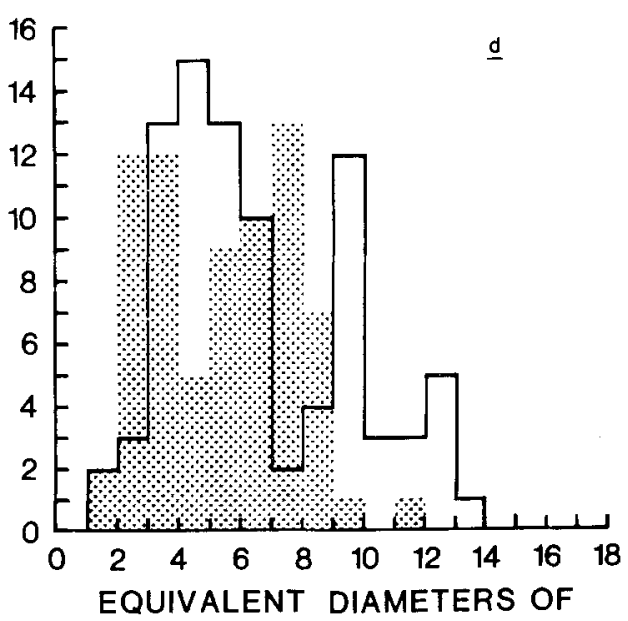

BASAL LAMINAS $(\mu \mathrm{m})$

Fig. 15. Histograms of the perimeters of the basal laminae $(p)$, converted to their equivalent diameters $(d)$ by the equation for a circle: $d=p / \pi$. The solid lines correspond to the diameters in the proximal nerve-stump; the stippled bars to the diameters in the distal stump. The histograms were made for one unlesioned nerve (a), for one nerve 2 days after crush (b) and for the two nerves at 8 days after crush that showed either the minimum (c) or maximum (d) amount of shrinkage of the basal laminae.

Degeneration at the site of crush

Light and electron microscopic examination of the approximately $300 \mu \mathrm{m}$ long zone at the site of crush revealed that after 1 day all of the myelin sheaths and axons were degenerating. The perineurial, endoneurial and Schwann cells were largely absent, and by 2 days there were numerous macrophages, often containing myelin debris, within and around the Schwann tubes. At the site of crush, the basal laminae of the Schwann tubes were flattened, irregular in outline and often full of myelin debris, but broken basal 
laminae (Haftek \& Thomas, 1968) were rarely observed. Thus, crushing destroyed all of the axons, myelin sheaths and cells of the connective tissue, but the basal laminae remained intact.

Degeneration in the proximal stump

During the first 2 weeks post-lesion, most of the myelinated axons in the proximal stump remained intact, although several alterations were noted. Between 1 and 4 days, some intact axons contained groups of clear and dense-cored vesicles, mitochondria and autophagic vacuoles, as others have described in detail (Blümcke et al., 1966; Zeleńa et al., 1968; Kapellar \& Mayor, 1969; Morris et al., 1972; Matthews, 1973). Between 4 and 13 days, many intact axons were indented or surrounded by adaxonal Schwann cell processes, which phagocytose portions of the axoplasm according to Spencer \& Thomas (1974). A few Schwann cells that surrounded apparently intact myelin sheaths and axons, but which contained myelin debris and lipid droplets, were observed as late as 31 days.

Frankly degenerative changes were also found in the proximal stump. Between 2 and 13 days post-lesion, we occasionally observed large (3-10 $\mu \mathrm{m}$ in diameter) single axons that lacked a myelin sheath, but were instead surrounded by one or more Schwann cells that typically contained myelin debris and lipid droplets. We interpreted them to be demyelinated axons, as they looked like unlesioned axons and not like growth cones. Degenerating myelinated axons, simliar to those already in the distal stump, were most numerous near the lesion, but a few, typically the largest axons, were found $2 \mathrm{~mm}$ or more centrally. Demyelination and retrograde degeneration over such distances has been described before (Ramón y Cajal, 1928; Morris et al., 1972). That the largest myelinated axons degenerated the furthest is consistent with the evidence that they probably had the longest internodes (Thomas \& Young, 1949), as axons often degenerate retrogradely to the nearest node (Ramón y Cajal, 1928; Lubińska, 1959).

\section{REGENERATIVE CHANGES IN THE NERVE}

Axonal regeneration in the distal stump following crush

A few non-myelinated axons were observed in the distal stump 2 days after crush. Even at 4 and 8 days, when their number had increased markedly (Fig. 37a), they were found almost exclusively within the Schwann tubes. Between 2 and 4 days, some of the non-myelinated axons looked like growth cones (Estable et al., 1957; Wettstein \& Sotelo, 1963; Yamada et al., 1971; Bunge, 1973; Al-Ghaith \& Lewis, 1982). They were characterized by abundant agranular endoplasmic reticulum, clear and dense-cored vesicles, mitrochondria, but few neurofilaments or microtubules (Figs. 16-21). There were solitary growth cones (Figs. 16, 19, 20), as well as ones that were part of a fascicle of non-myelinated axons (Figs. 17, 18, 21). Although growth cones varied greatly in shape, all of the 20 or so found in our material contacted the inner surface of a basal lamina, sometimes only slightly (Figs. 17, 18), and sometimes quite extensively, as in Figs. 16, 19-21. 
Between 4 and 8 days, the non-myelinated axons were typically packed in fascicles, in which the individual axons were closely fitted together like pieces of a puzzle (Figs. 18, 21-23). These fascicles were usually located at the margin of the Schwann tubes, but the fascicles, unlike the growth cones, were usually separated from the inner surface of the basal lamina by Schwann cell processes (Figs. 18, 22-24). Between 2 and 4 days, these non-myelinated axons had a characteristic ultrastructure, intermediate between growth cones and unlesioned axons: they contained agranular endoplasmic reticulum, clear and dense-cored vesicles, mitochondria, microtubules and an occasional dense body, autophagic vacuole or multivesicular body, all of which typically surrounded a cluster of neurofilaments (Fig. 18). At 8 days, most of the non-myelinated axons had a more

Fig. 16. (a) A growth in the proximal nerve-stump. This Schwann tube contains myelin debris ( $\star$ ), but no Schwann cells. A growth cone (between arrowheads) extends $24 \mu \mathrm{m}$ around the inner surface of the basal lamina. The regions between the arrows (labelled $b-d$ ) correspond to Fig. $16 \mathrm{~b}-\mathrm{d}$. About $50 \mu \mathrm{m}$ proximal to the lesion, 1 day after crush. (b-d) Details of the growth cone. The growth cone, which contains clear and dense-cored vesicles, mitochondria $(\star)$ and agranular endoplasmic reticulum, is directly apposed to the inner surface of the basal lamina (arrows). c, Collagen fibres. Scale bars: $1 \mu \mathrm{m}$.

Fig. 17. A growth cone that is both outside ( $\star$ ) and inside a Schwann tube. The two parts of the growth cone are connected by a process (between arrowheads) that extends across the basal lamina (arrows). $\mathrm{m}$, Myelin debris. Distal stump, 4 days after crush, PTA post-fixation. Scale bar: $1 \mu \mathrm{m}$.

Fig. 18. A Schwann tube that contains a Schwann cell (s), 5 non-myelinated axons ( $\star$ ) and a large growth cone that contacts the inner surface of the basal lamina (between arrowheads). Distal stump, 4 days after crush, PTA post-fixation. Scale bar: $1 \mu \mathrm{m}$.

Figs. 19-21. Distal stump, PTA post-fixation, scale bars: $1 \mu \mathrm{m}$.

Figs. 19, 20. Two details of a crescent-shaped growth cone ( $\star$ ) that extended $33 \mu \mathrm{m}$ around the inner surface of a basal lamina (arrows). In the thickest part of the growth cone (Fig. 19), the characteristic organelles predominated, but the thinner part (Fig. 20) mostly contained finely granular material resembling that found in filopodia (Yamada et al., 1971). The Schwann cell (s) beneath the growth cone contains myelin debris $(d)$.

Fig. 21. A detail of a growth cone that extended $10 \mu \mathrm{m}$ around the inner surface of a basal lamina (arrows). Note that the 3 non-myelinated axons (a), whose growth cones presumably were even more distal, are surrounded by Schwann cell processes (s).

Fig. 22. A Schwann tube that contains one Schwann cell (s), 3 Schwann cell processes (arrows) and 4 non-myelinated axons $(\star)$. The endoneurium contains hypertrophied fibroblasts $(e)$ and a macrophage that surrounds myelin debris $(\mathrm{m})$. Crush site, 8 days post-lesion. TA post-fixation. Scale bar: $1 \mu \mathrm{m}$. Inset: detail of area enclosed by the rectangle. One Schwann cell process contains a cluster of tightly packed, $10 \mathrm{~nm}$ filaments (arrowhead) that are not interconnected by wispy material. The arrow points to the basal lamina, which is particularly well stained. Scale bar: $1 \mu \mathrm{m}$.

Fig. 23. A Schwann tube that contains 6 non-myelinated axons ( $\star$ ), 1 remyelinated axon and 2 Schwann cells (s). Regions of compact myelin are joined to each other by regions containing several layers of thin, circumferentially disposed processes. The Schwann cells are partially separated (between arrowheads) and patches of basal lamina are found within this gap. Distal stump, 8 days after crush. Scale bar: $1 \mu \mathrm{m}$. 

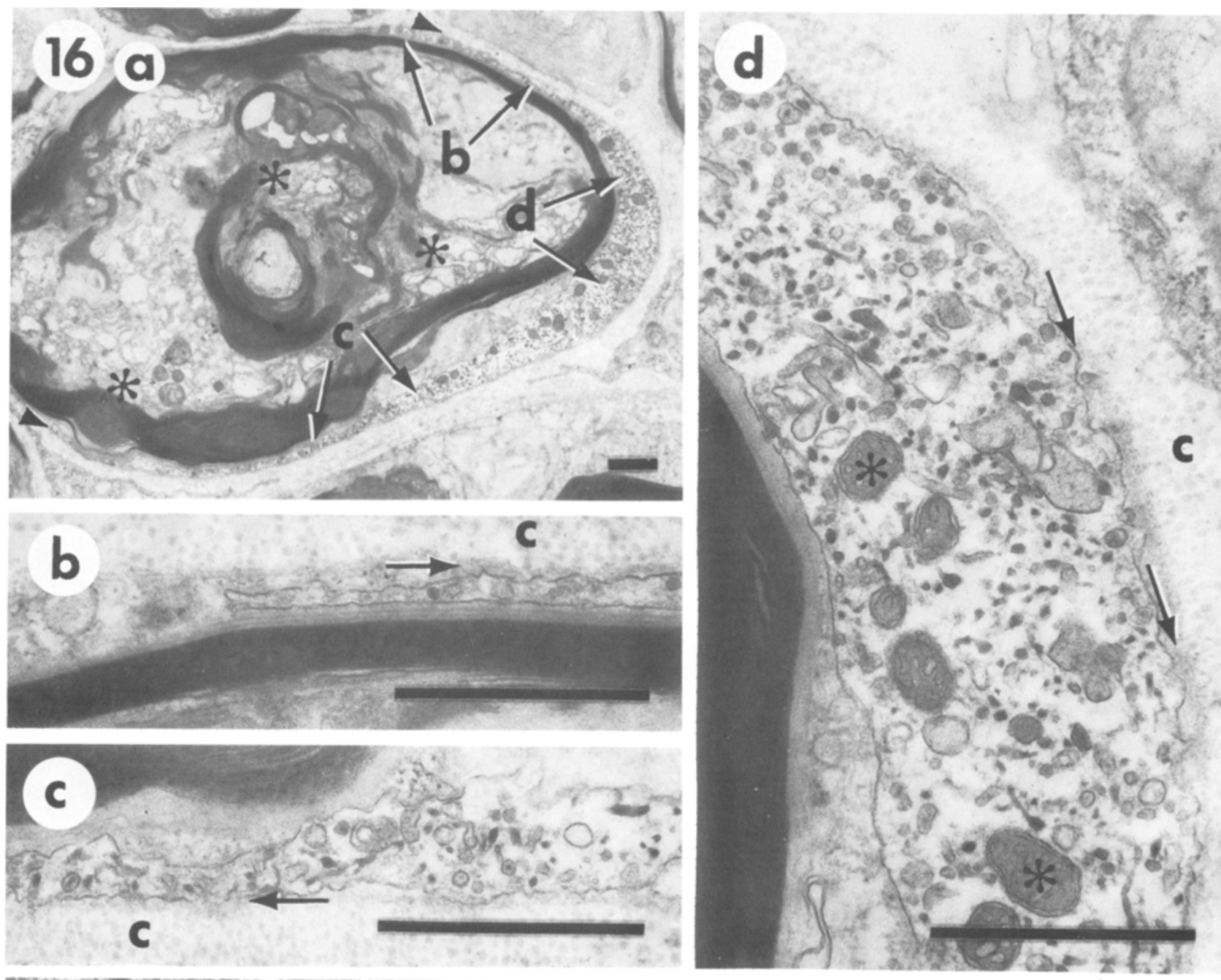

\section{c}

(6) 6.0

\section{C}

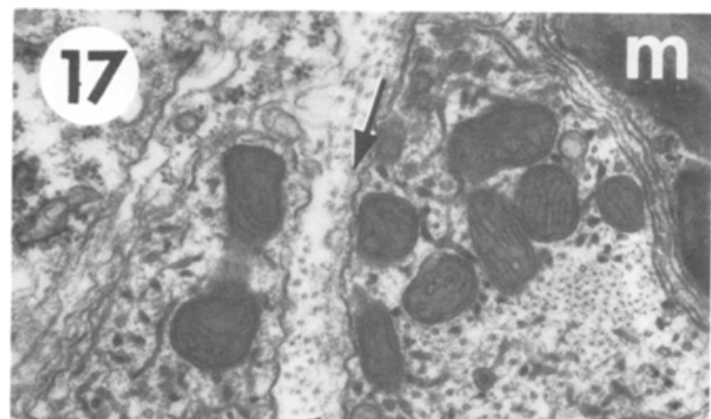

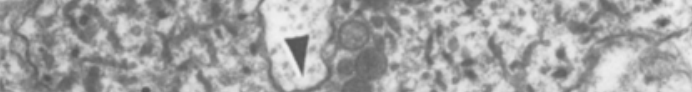

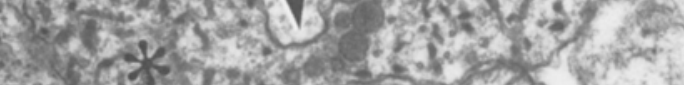
a a 3) pos

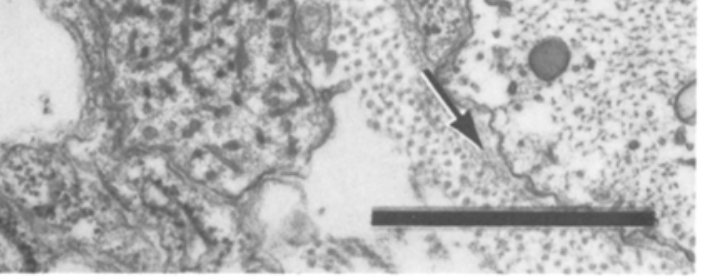

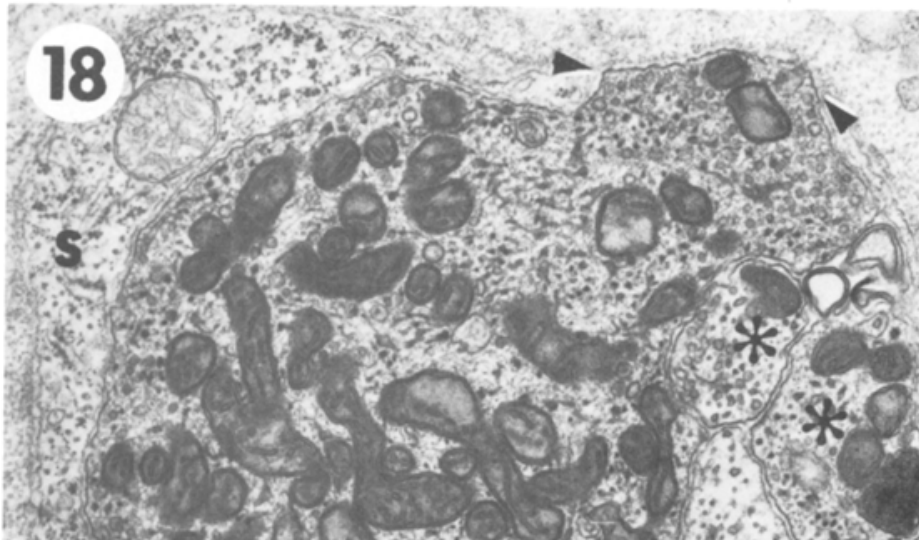

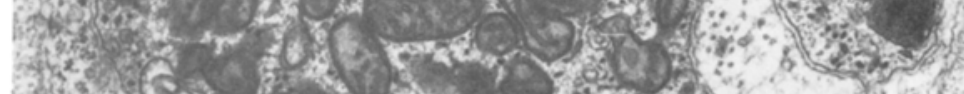

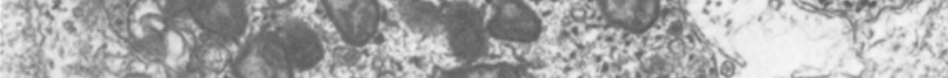

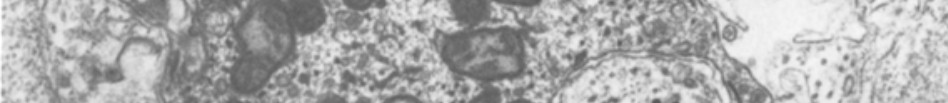

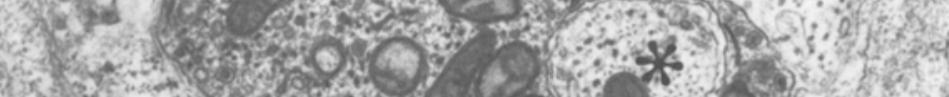

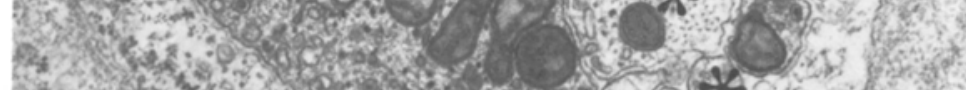
3 .

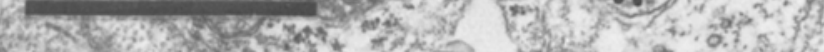


19

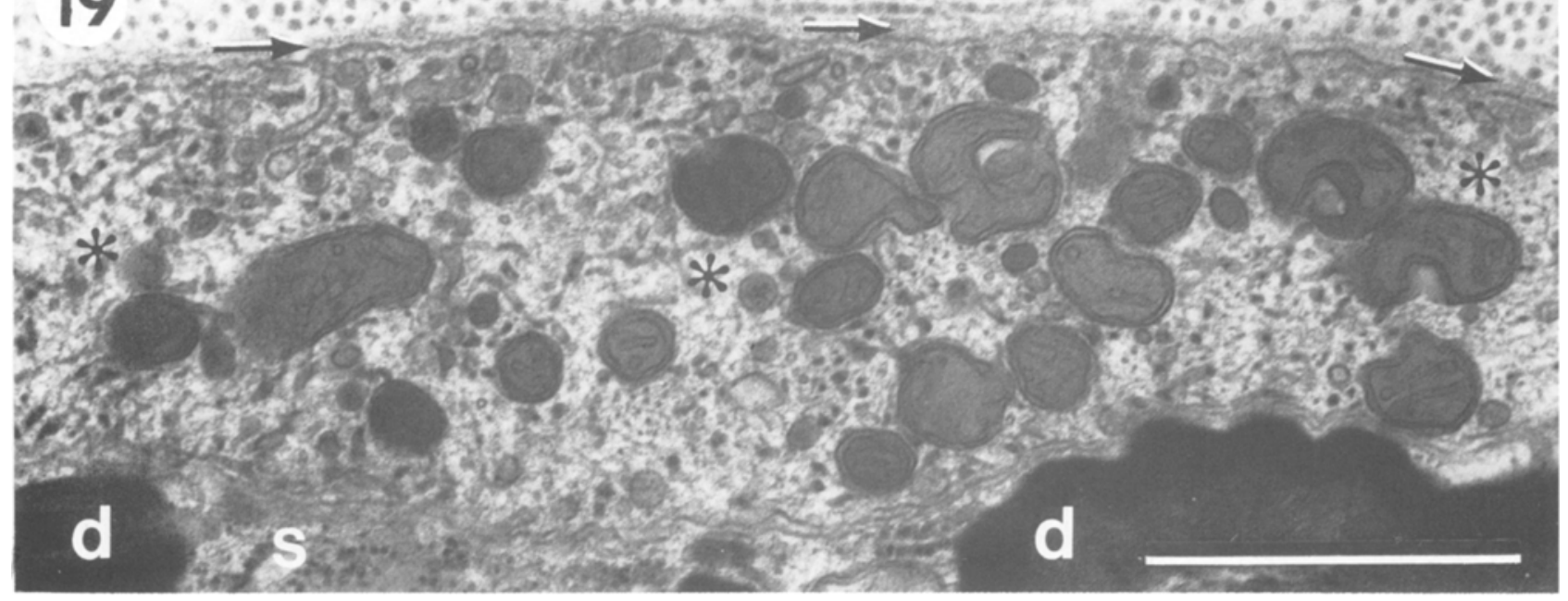

\section{0 .}

(2)

…ㄴ.

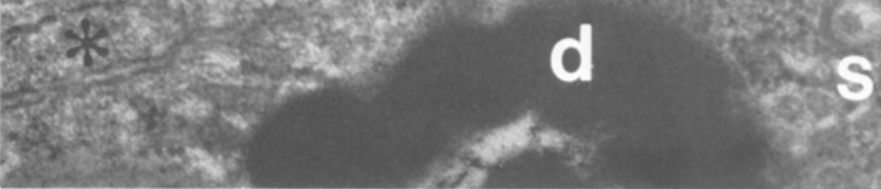

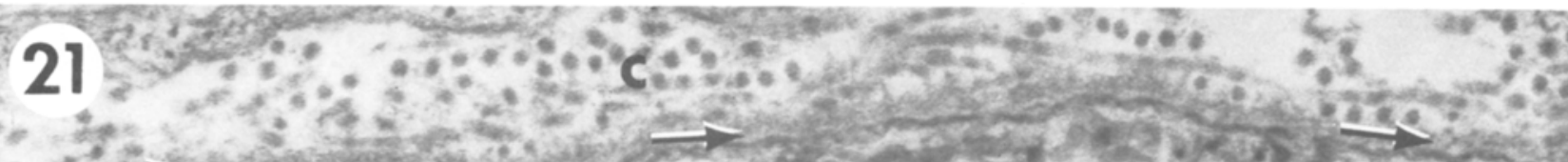

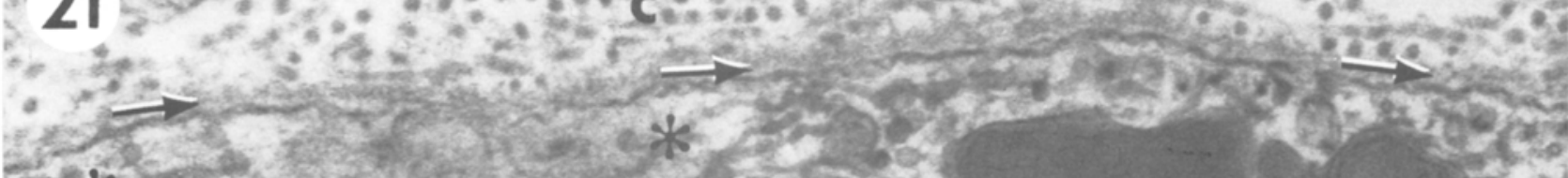
Hection

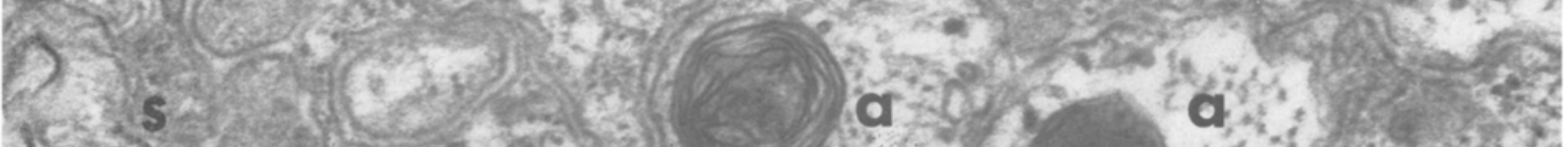

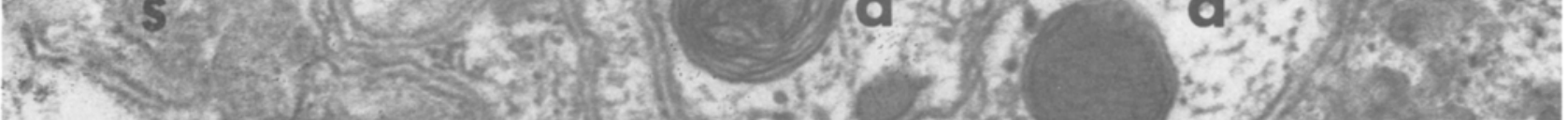

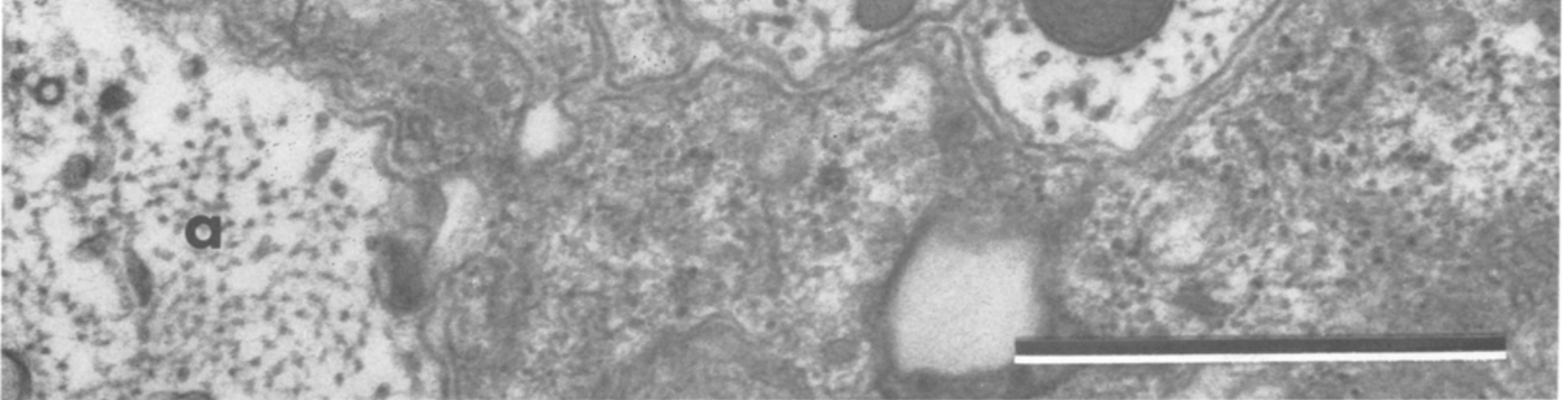



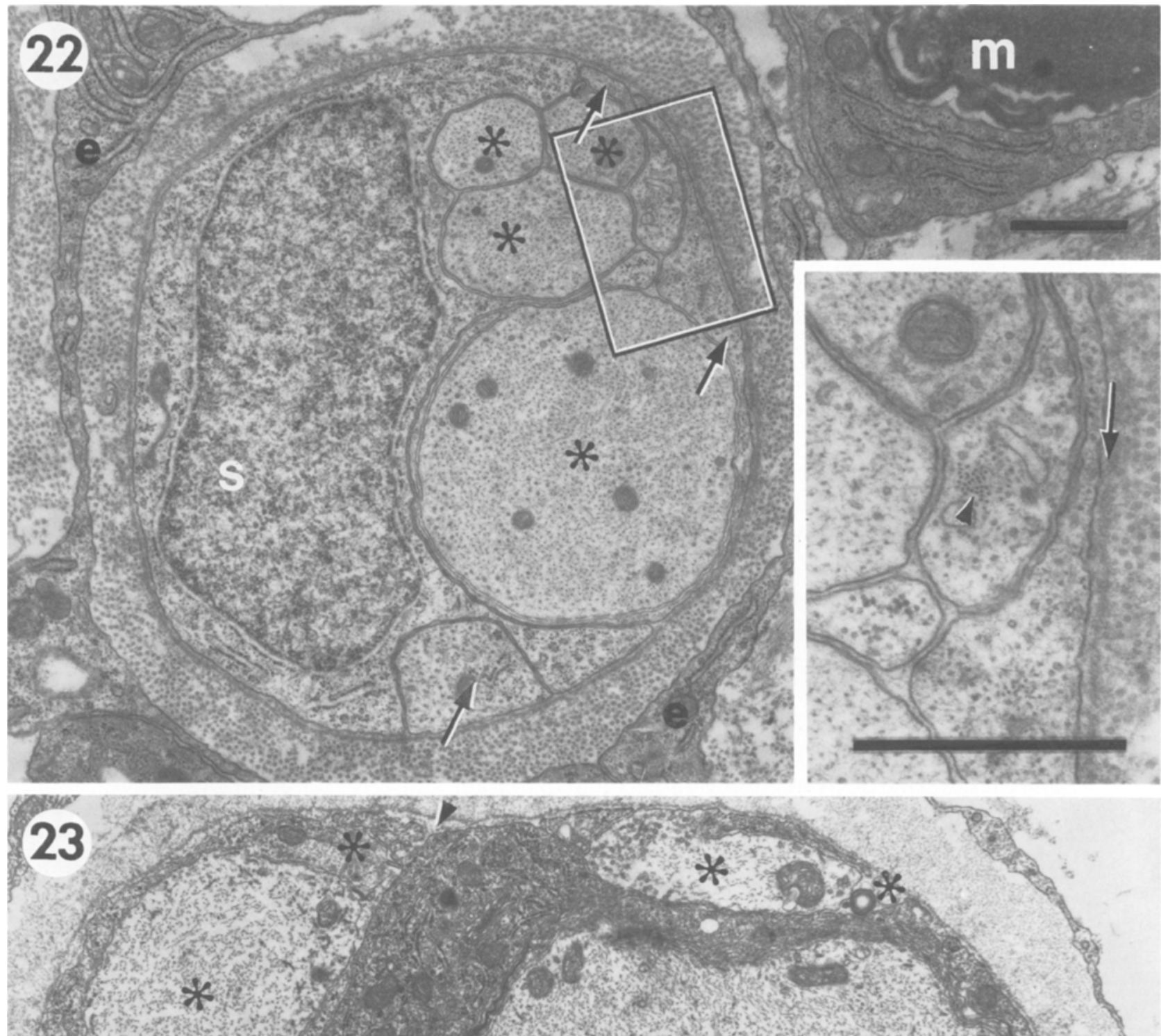

(2). $* 13$

( 5
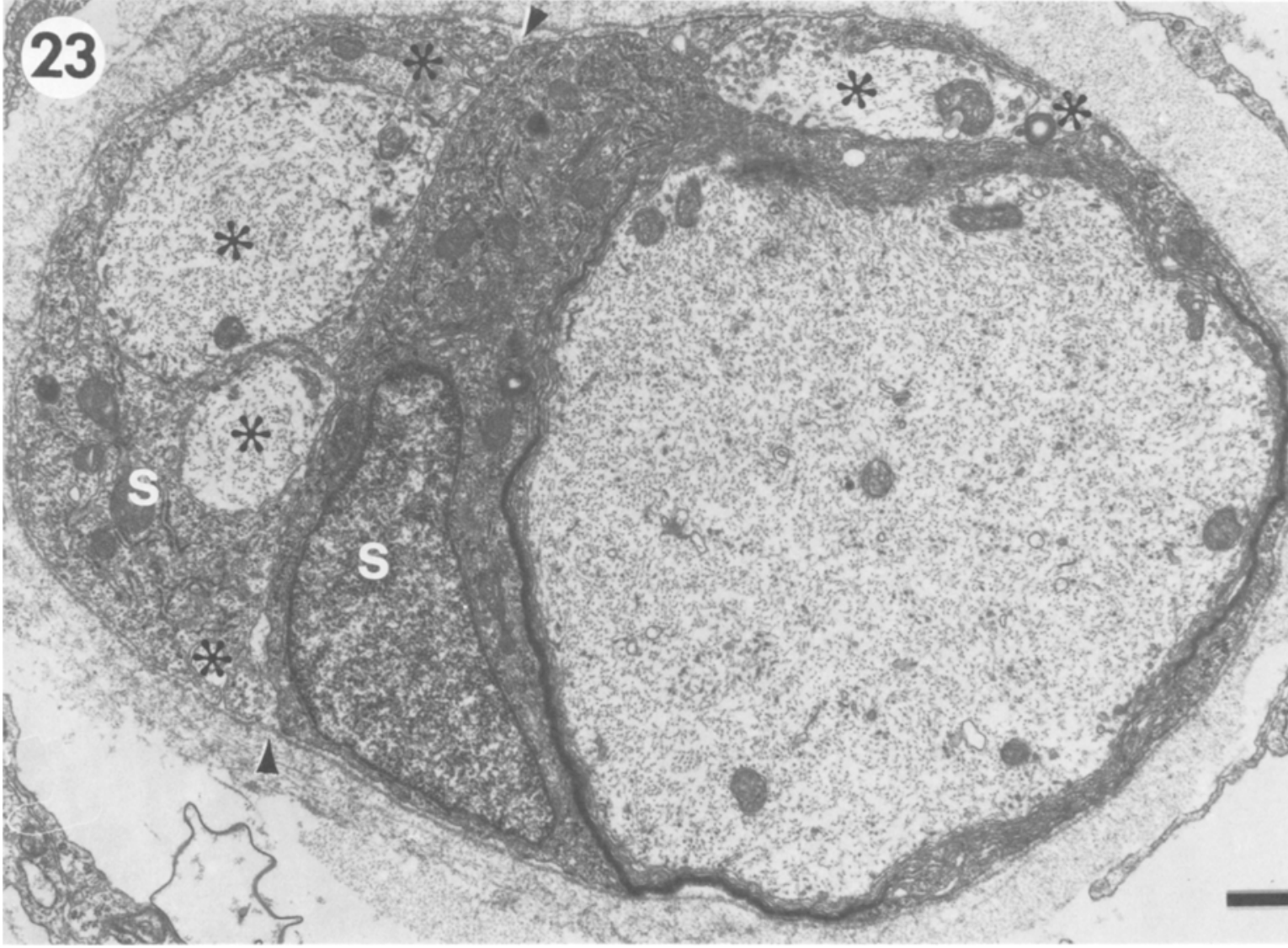
mature appearance. They consisted mostly of neurofilaments and a few microtubules; clear and dense-cored vesicles, agranular endoplasmic reticulum and dense bodies were sparse (Figs. 22, 23). Processes of Schwann cells surrounded and separated the axons, thereby dividing them into smaller groups (Figs. 22, 23). The largest non-myelinated axons were often completely isolated from the others by Schwann cell processes (Figs. 22, 23), often 1-4 layers thick (Fig. 23); these layered processes were the probable precursors of compact myelin.

\section{Remyelination and the breakdown of the Schwann tubes}

Several remyelinated axons were observed at 8 days, usually the largest axons in the Schwann tube (Fig. 23). The other non-myelinated axons within the Schwann tube were either tangentially related to the Schwann cells of the remyelinated axons (Fig. 23), associated with another Schwann cell (Figs. 23-25) or without any Schwann cell investment (Fig. 25). The size of the smallest remyelinated axons decreased between 4 and 31 days, and small (1-3 $\mu \mathrm{m}$ in diameter) remyelinated axons were numerous at 31 days. A few of these small remyelinated axons had redundant myelin loops, which have been described in developing peripheral nerves (Webster, 1971). The thickness of the myelin sheath was progressively greater at $8,13,31$ and 107 days for remyelinated axons of all diameters; by 107 days most of the myelin sheaths were only modestly thinner than those of equally sized axons of unlesioned nerves.

At 8 days, individual Schwann cells were sometimes partially separated from adjacent ones in the same Schwann tube by a thin gap up to $1 \mu \mathrm{m}$ wide (Fig. 23). At 13 days, a few Schwann cells were completely separated from the others, and a thin, often incomplete basal lamina and some longitudinally orientated collagen fibres were usually found

Figs. 24-26. Distal stump, scale bars: $1 \mu \mathrm{m}$.

Fig. 24. A Schwann tube that contains 2 remyelinated and 2 non-myelinated axons $(\star), 5$ Schwann cell processes (arrows) and 2 Schwann cells. The membranous debris (double arrowhead) may be a degenerating axon. Note the prominent Golgi complexes (g). A gap partially separates two Schwann cells (between arrowheads), but the basal lamina and the collagen fibres within the gap are not well stained; 13 days after crush.

Fig. 25. The basal lamina of a Schwann tube is outlined by the dotted line, which surrounds 2 remyelinated and 2 non-myelinated axons $(\star)$. One non-myelinated axon is not surrounded by Schwann cell processes. The membranous debris (arrows) was continuous with a degenerating unmyelinated axon in adjacent sections. TA post-fixation, 31 days after crush. Inset: detail of the area enclosed by the rectangle. The non-myelinated axon is surrounded by a Schwann cell process (arrow), patches of basal lamina (arrowheads) and collagen fibres (c). The basal lamina and collagen fibres are presumed to have been synthesized after the lesion because they are not continous with the basal lamina of the Schwann tube.

Fig. 26. A remyelinated axon ( $\star$ ) that is partly surrounded by a crescent of Schwann cell processes, some of which contain clusters of $10 \mathrm{~nm}$ filaments (arrows). The processes are surrounded by a basal lamina (arrowheads) and collagen fibres (c); 31 days after crush. 


\section{4}

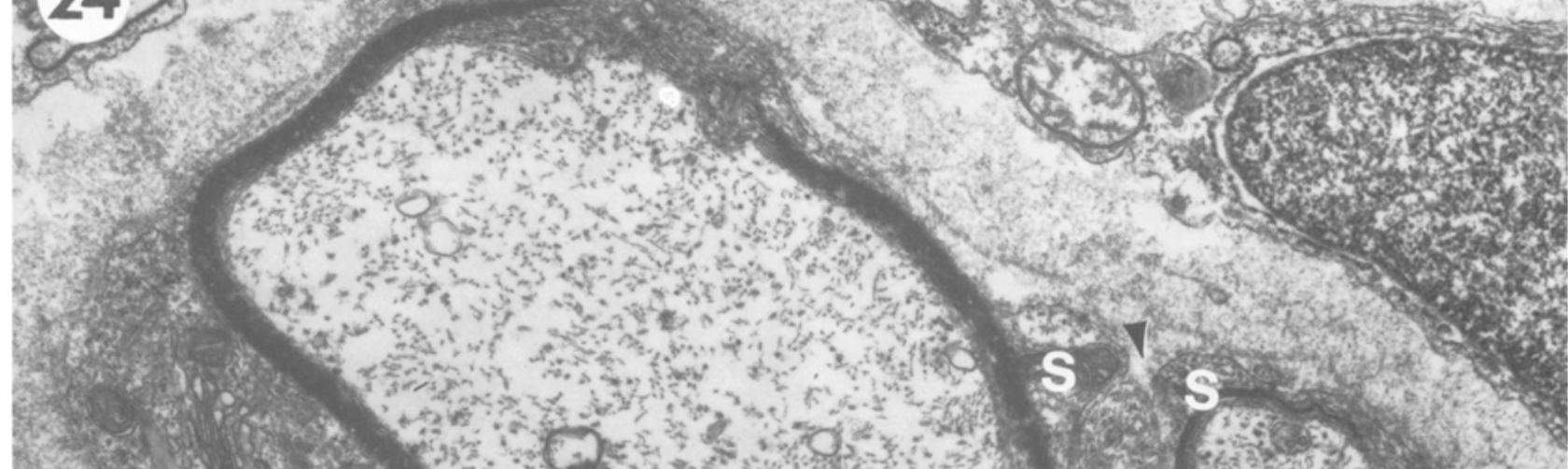

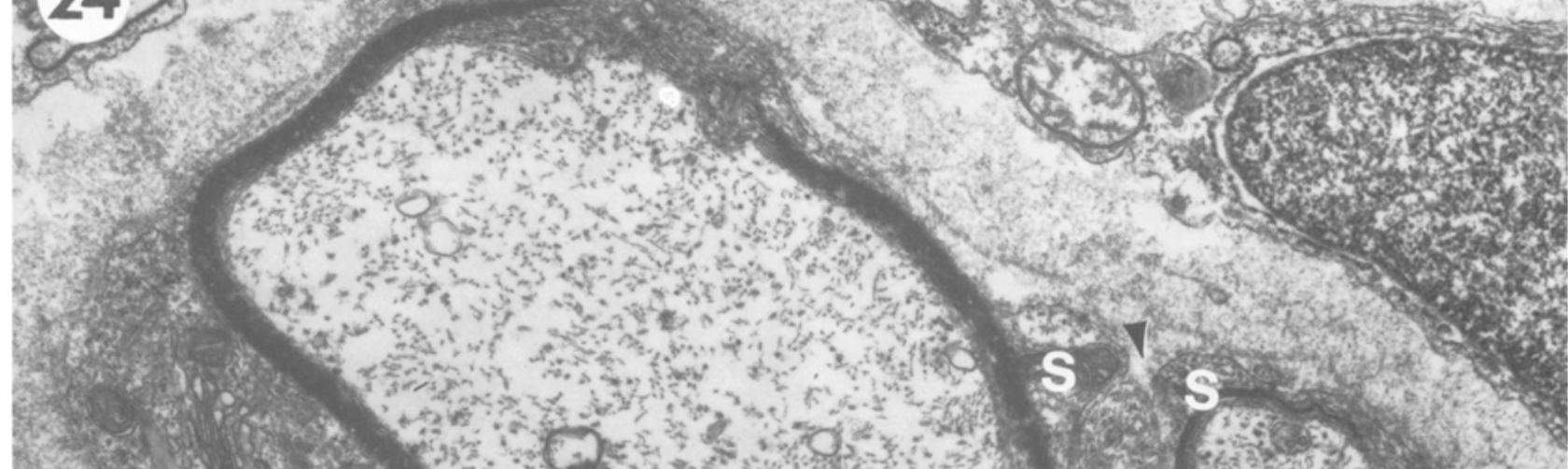

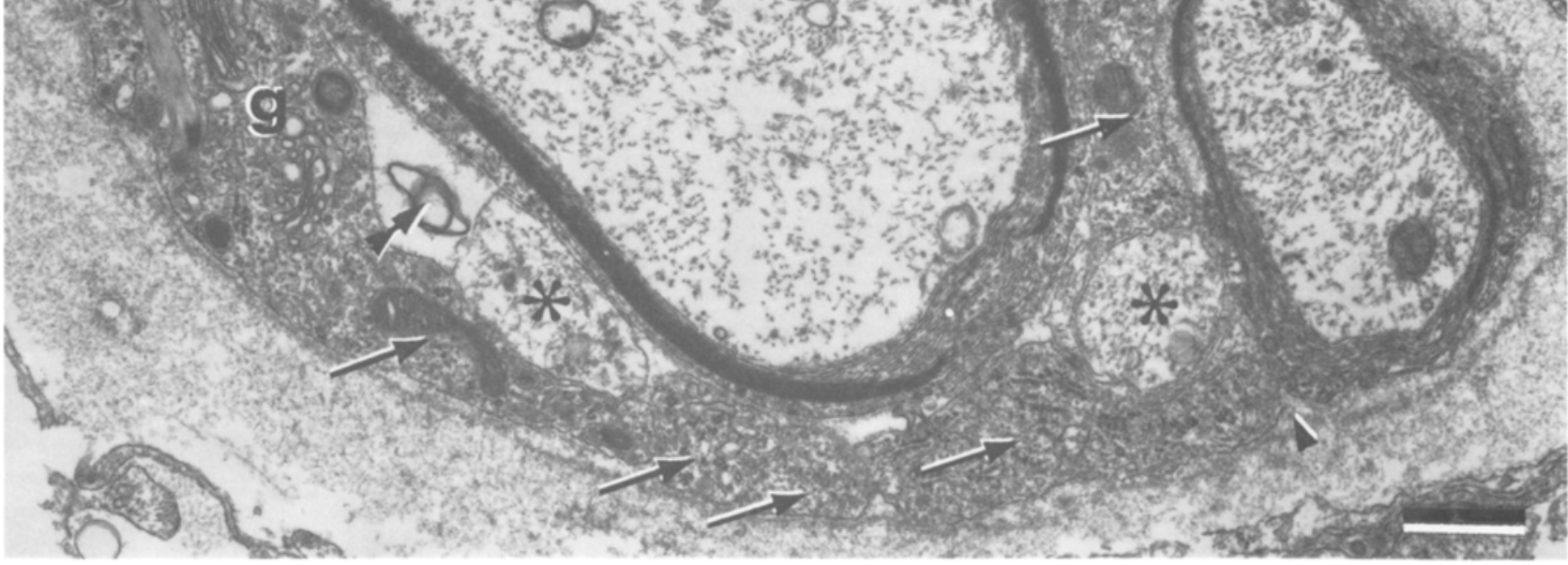
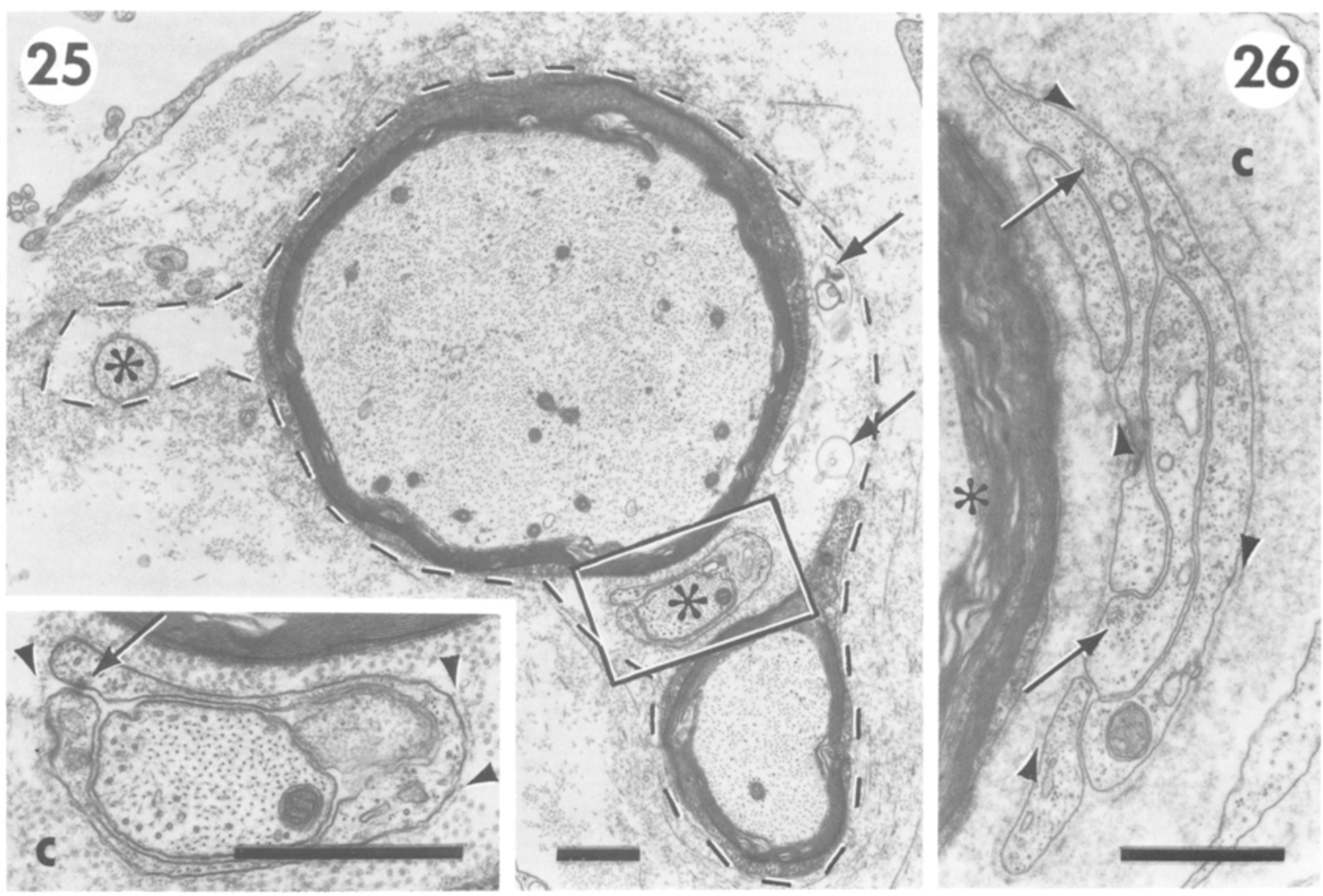
between the separated cells (Fig. 24). Only Schwann cells associated with remyelinated axons were separated in this manner; those associated with non-myelinated axons were still tightly packed together within a common basal lamina (Figs. 23, 24). At 31 days, more remyelinated axons were individually surrounded by a basal lamina and collagen fibres (Fig. 25), yet other groups of small remyelinated and non-myelinated axons were still surrounded by a common basal lamina. Although the close proximity of many remyelinated axons suggested a common origin from one Schwann tube, a single basal lamina that surrounded all of them was rarely preserved as it is in Fig. 25. At 107 days, a basal lamina individually surrounded almost all of the remyelinated axons, which in many cases remained grouped together. In summary, the larger axons in the Schwann tubes were remyelinated and surrounded by a basal lamina $2-4$ weeks before the smaller ones, yet both large and small axons were well myelinated by 107 days.

The number of basal laminae in the distal stump increased concomitantly with remyelination (Fig. 37d), as each remyelinated axon acquired its own basal lamina.

Degeneration of non-myelinated axons

At 8,13 and especially at 31 days after crush, we occasionally observed non-myelinated axons containing accumulations of clear and dense-cored vesicles, dense bodies and mitochondria (Figs. 28, 29) and other profiles containing flocculent or membranous material (Figs. 26, 27). All of these profiles were probably non-myelinated axons at

Figs. 27-29. Putative degenerating non-myelinated axons in the distal stump. Scale bars: $1 \mu \mathrm{m}$.

Fig. 27. A portion of a Schwann tube that contains a remyelinated axon ( $\star$ ) and membranous debris (double arrowhead) surrounded by a basal lamina (arrow); 13 days after transection.

Figs. 28, 29. Non-myelinated axons (arrows) that contain accumulations of clear and dense-cored vesicles, mitochondria and dense bodies, adjacent to well-fixed axons ( $\star$ ). TA post-fixation, 31 days after crush.

Figs. 30-33. Putative collateral sprouts in the proximal stump. Scale bars: $1 \mu \mathrm{m}$.

Fig. 30. A non-myelinated $(*)$ and a remyelinated axon surrounded by a common basal lamina and separated from an adjacent, intact myelinated axon $(\mathrm{m})$ by a gap (between arrowheads) that contains collagen fibres. The non-myelinated axon is not surrounded by a Schwann cell process. TA post-fixation, 31 days after crush.

Fig. 31. A non-myelinated axon ( $\$$ ) and a Schwann cell (s) that are separated from an adjacent, intact myelinated axon $(\mathrm{m})$ by a gap that contains collagen fibres (between arrowheads). 13 days after crush.

Fig. 32. A non-myelinated axon ( $\star$ ) that is enveloped by the cytoplasm of a Schwann cell that forms a myelin sheath $(\mathrm{m})$ around an intact axon. Note the coated pit (arrowhead) and the basal lamina (arrow). TA post-fixation, 31 days after crush.

Fig. 33. A longitudinal section through an intact axon (above), its myelin sheath ( $\mathrm{m}$ ), and a non-myelinated axon (below) that is adjacent to the inner surface of the basal lamina (arrow). Both axons contain longitudinally orientated agranular endoplasmic reticulum (arrowheads) and neurofilaments (f), to which the wispy material is orthogonally related. 3 days after crush. 


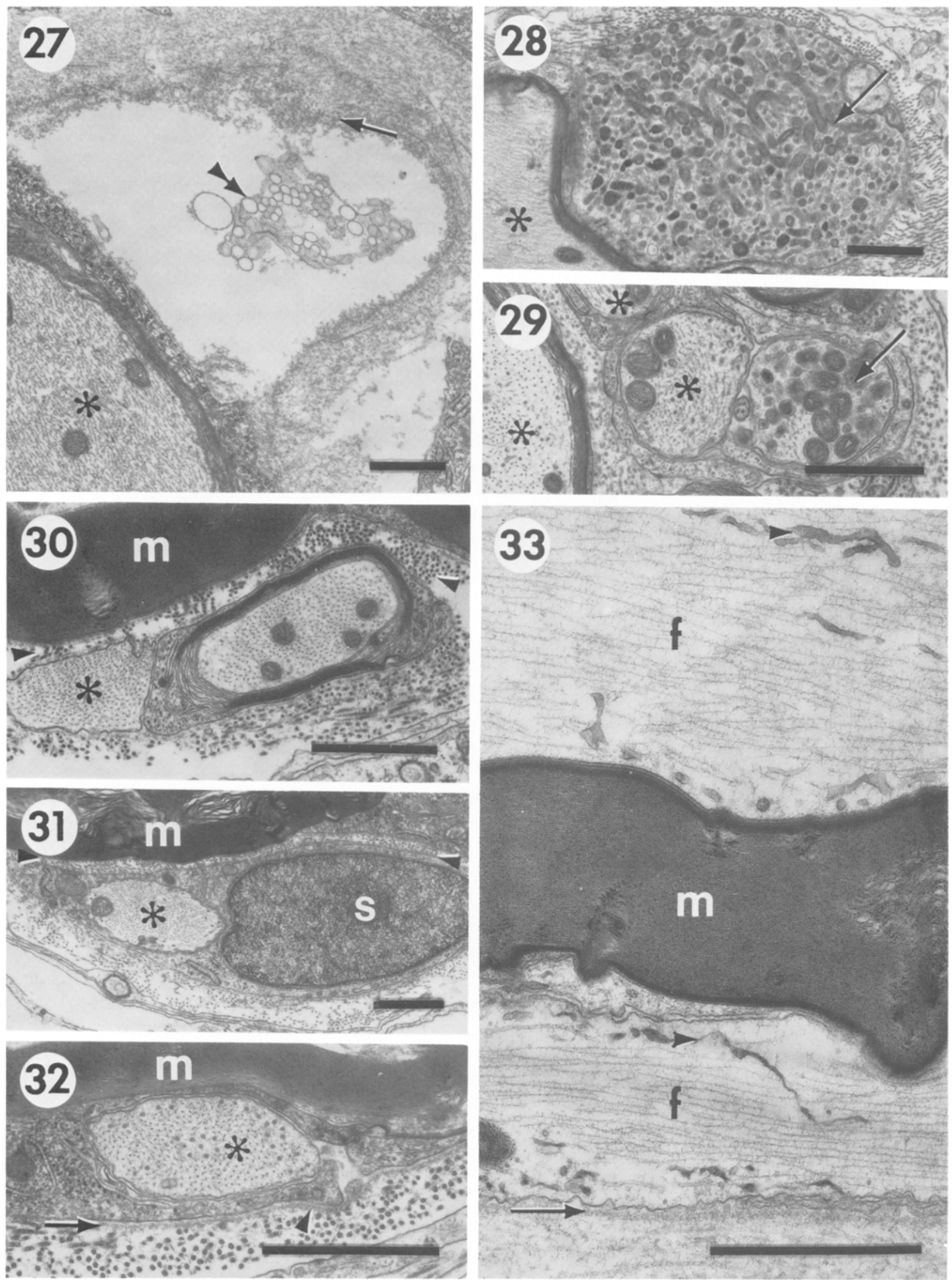


various stages of degeneration, as they were similar to descriptions of degenerating non-myelinated and unmyelinated axons (Mire et al., 1970; Berger, 1971; Dyck \& Hopkins, 1972; Matthews, 1973; Thomas \& King, 1974; Chu-Wang \& Oppenheim, 1978). The degeneration of non-myelinated axons might account for the presence of Schwann cells that were not associated with any axons (Fig. 26) between 31 and 107 days. These Schwann cells may have originally been associated with non-myelinated axons that later degenerated, as Hall (1973) has previously described.

Not all of the non-myelinated axons degenerated. Even at 107 days, there were non-myelinated axons scattered throughout the distal stump, typically within crescents of Schwann cell processes that were adjacent to remyelinated axons (Fig. 26), reminiscent of those described by King \& Thomas (1971). Here our distinction between non-myelinated and unmyelinated axons broke down, as these 'non-myelinated axons' could have been either the distal continuation of unmyelinated axons or the branches of myelinated axons that had not degenerated or remyelinated.

The absence of degenerating remyelinated axons between 8 and 107 days suggests that once having been myelinated, an axon was maintained. This suggestion is consistent with our quantitative analysis, which showed no loss of remyelinated axons (see below).

Regeneration at the site of crush

At 2, 4 and 8 days, the majority of the non-myelinated axons at the site of crush were found within the Schwann tubes; the $1-5 \%$ that were not, the so-called 'extra-tubal sprouts' (Ramón y Cajal, 1928), were found either singly or in fascicles, adjacent to perineurial or endoneurial cells (Fig. 17), and a few were even outside the perineurium. They were ultrastructurally similar to other non-myelinated axons, except that many of them were degenerating (see above) and orientated obliquely with respect to the nerve. They were most numerous near the site of crush, presumably because of the greater mechanical damage there, but a few were found in the proximal and distal stumps (Fig. 17); they were rarely observed anywhere at 13 days or thereafter.

Regeneration in the proximal stump

Between 1 and 31 days after crush, we found non-myelinated axons within the basal laminae of the degenerating myelinated axons in the proximal stump, especially within $1 \mathrm{~mm}$ or less of the site of the lesion. These non-myelinated axons were ultrastructurally similar to those in the distal stump, and their number per Schwann tube was comparable (range in the proximal and distal stumps: 0-20 v. 0-25, respectively). At 8 days, remyelinated axons were observed; at 13 days, some of them were separated from the rest of the cells of the Schwann tube by a basal lamina; at 31 days, most of them were remyelinated. Hence, the number, appearance and maturation of non-myelinated axons in the proximal stump were similar to that in the distal stump.

Between 3 and 31 days, we also observed non-myelinated axons within the basal laminae of intact myelinated axons in the proximal stump (Fig. 32). Other axons were 
separated from the Schwann cell of the intact myelinated axon by either a basal lamina alone (not shown), a basal lamina and Schwann cell processes (not shown) or a basal lamina, Schwann cell processes and a gap containing collagen fibres (Figs. 30, 31); some of these axons were even remyelinated (Fig. 30). These axons probably were the collateral and recurrent terminal sprouts of the myelinated axon with which they were associated (Ramón y Cajal, 1928); examples of both possibilities were seen in longitudinal sections (see also Friede \& Bischhausen, 1980). Even if all of them were collateral sprouts that had reached the distal stump, they could only account for a small fraction of the total there. At 2-4 mm central to the lesion, there were 1-6 of them associated with only $3 \%$ of the intact myelinated axons (usually the largest ones) between 4 and 31 days; within less than $1 \mathrm{~mm}$ of the lesion, less than $1 \%$ of the intact myelinated axons were associated with a remyelinated collateral sprout at 31 days, the time at which the number of remyelinated axons in the distal stump was at a maximum. Hence, collateral sprouts probably contributed only a few axons to the distal stump. It follows, therefore, the terminal sprouting from the ends of axons in the proximal stump gave rise to most of the regenerating axons in the distal stump (Ramón y Cajal, 1928; Zelena et al., 1968), as only a limited amount of axonal branching occurred within the distal stump itself (see below).

Regeneration in transected nerves

Following transection, the proximal and distal stumps remained roughly aligned, although they were separated by a narrow gap of not more than a few hundred micrometres wide. At 4 and 8 days, this gap contained hundreds of non-myelinated axons that were mostly found in large fascicles, which were usually adjacent to connective tissue cells of an unknown derivation. There were no basal laminae within the gap. Many growth cones were seen at 4 days; at 8 days, remyelinated axons were first observed. Although many obliquely orientated axons were observed, most axons appeared to run longitudinally with respect to the nerve. At 4 days, there were few, if any, axons in the Schwann tubes of the distal stump, but at 8 days there appeared to be as many as in crushed nerves, although we did not systematically count them. Thus, in spite of the disorganization of the axons and the absence of Schwann tubes at the site of transection, the axons were, nevertheless, found almost exclusively within the Schwann tubes in the distal stump.

Changes in the connective tissue

We observed several changes in the connective tissue of the nerve in both the proximal and distal stumps after cutting or crushing the nerve. In agreement with previous reports (Williams \& Hall, 1972; Morris et al., 1972; Rawlins et al., 1972; Weinberg \& Spencer, 1978), we found lipid droplets and more rough endoplasmic reticulum in both perineurial and endoneurial cells during the first two weeks post-lesion (Fig. 22). The amount of collagen associated with the Schwann tubes increased between 4 and 107 days, owing to the deposition of collagen fibres within the basal laminae, especially around the newly formed basal laminae (Fig. 25) (Nathaniel \& Pease, 1963c; Thomas, 1964; Morris et al., 1972). 


\section{REINNERVATION OF THE SUPERIOR OBLIQUE MUSCLE}

The superior oblique muscle consists of large, spiking and small, non-spiking muscle cells, both of which are polyneuronally innervated (Kilarski \& Bigaj, 1969; Scott, 1977). Since individual muscle cells extend the entire length of the muscle and are innervated at sites that are evenly distributed along its length (Davey et al., 1975; Easter, 1979), we could estimate the extent of innervation by examining one region electron microscopically.

In unlesioned animals, the nerve terminals usually occupied a shallow gutter on the surface of the muscle cell; the two were separated by a basal lamina. Clear vesicles filled the region of the terminal adjacent to the muscle cell, whereas mitochondria, dense-cored vesicles and cytoskeletal elements tended to occupy the region furthest from it. The post-junctional membrane lacked elaborate folds, but had a prominent density that helped to identify the site of the original endplate in lesioned animals.

At 2 days after crush, most of the intramuscular myelinated axons appeared similar to the degenerating ones in the distal stump. At 4 days, the Schwann tubes in the large, intramuscular branches contained non-myelinated axons, and at 8 days, most of the solitary Schwann tubes, which were presumably more distal, also contained them. Remyelinated axons were first observed at 13 days, and at 31 days they were separated from the other axons of the Schwann tube by a basal lamina. Thus, reinnervation in the intramuscular nerves appeared similar to regeneration in the distal stump, although it was slightly delayed in time. Although non-myelinated axons appeared to regenerate almost exclusively within the Schwann tubes, we may have failed to detect 'escaped' axons (Gutmann \& Young, 1944) because they too are surrounded by Schwann cells (Letinsky et al., 1976).

At 2 days after crush, there were almost no intact axonal terminals; instead, Schwann cells usually occupied the endplate (Fig. 34). The first regenerated terminals were found at 8 days, on both large and small muscle cells (Fig. 35). Many of these terminals looked like growth cones, and generally they were smaller and contained fewer synaptic vesicles than the original ones. Unlike the endplates in unlesioned animals, some of the endplates (less than 10\%) appeared to contain more than one axon (Fig. 35), and these

Figs. 34-36. Transverse sections of the superior oblique muscle. TA post-fixation. Scale bars: $1 \mu \mathrm{m}$.

Fig. 34. A Schwann cell (s) surrounded by a basal lamina (arrows), lies on top of a muscle cell (m) in a shallow depression, which probably was the original site of an endplate; 8 days after crush.

Fig. 35. A Schwann cell (s) associated with 3 axonal processes $(\star), 2$ of which contain synaptic vesicles and contact the basal lamina (arrows) adjacent to the muscle cell (m); 8 days after crush.

Fig. 36. A regenerated neuromuscular junction that looks similar to those in unlesioned animals. A Schwann cell process (s) caps an axonal terminal that contacts the basal lamina of a muscle cell (m). Note the active zone (between arrowheads), where the pre- and postsynaptic densities coincide. The terminal contains clear and dense-cored vesicles and mitochondria $(\star)$. The arrow points to a coated pit. 31 days after crush. 


\section{4}

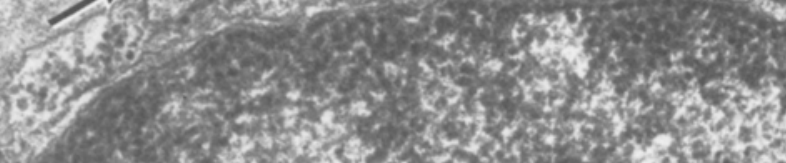

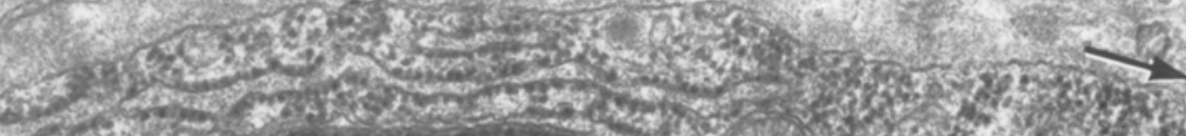
sey 10

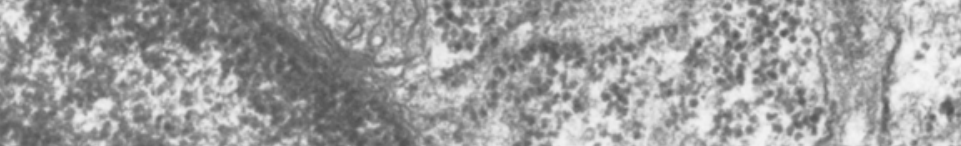

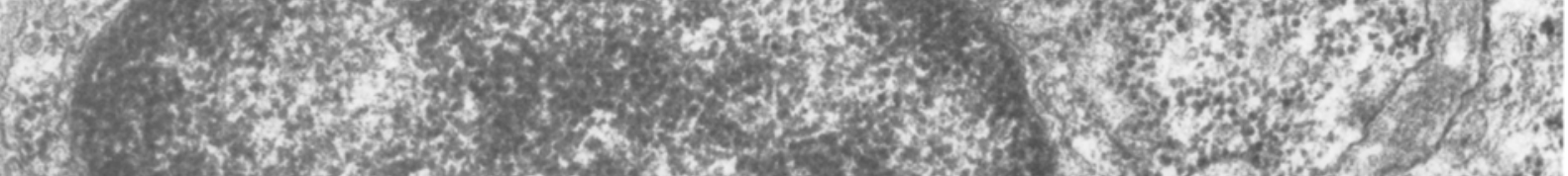

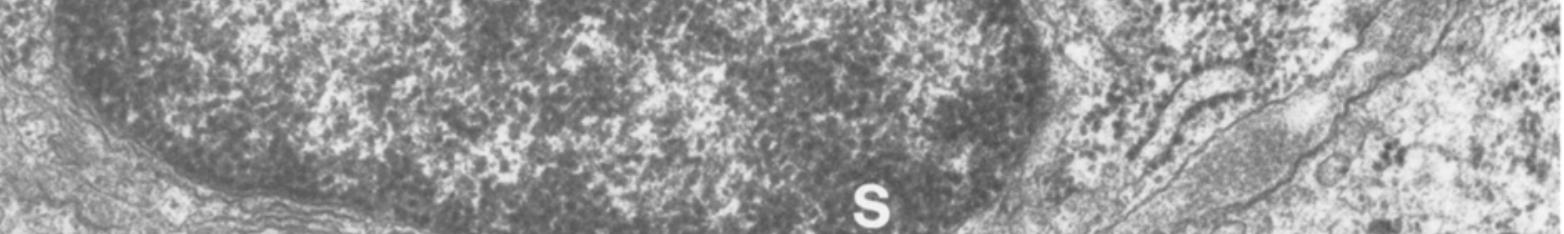
20
3

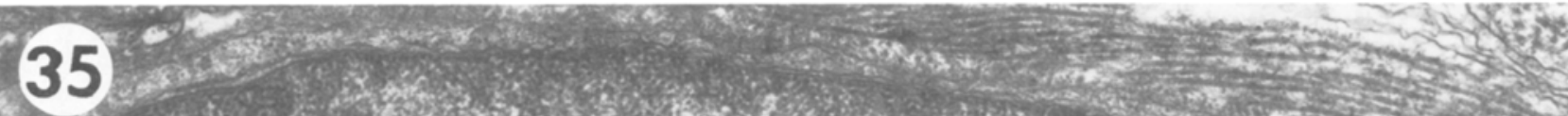

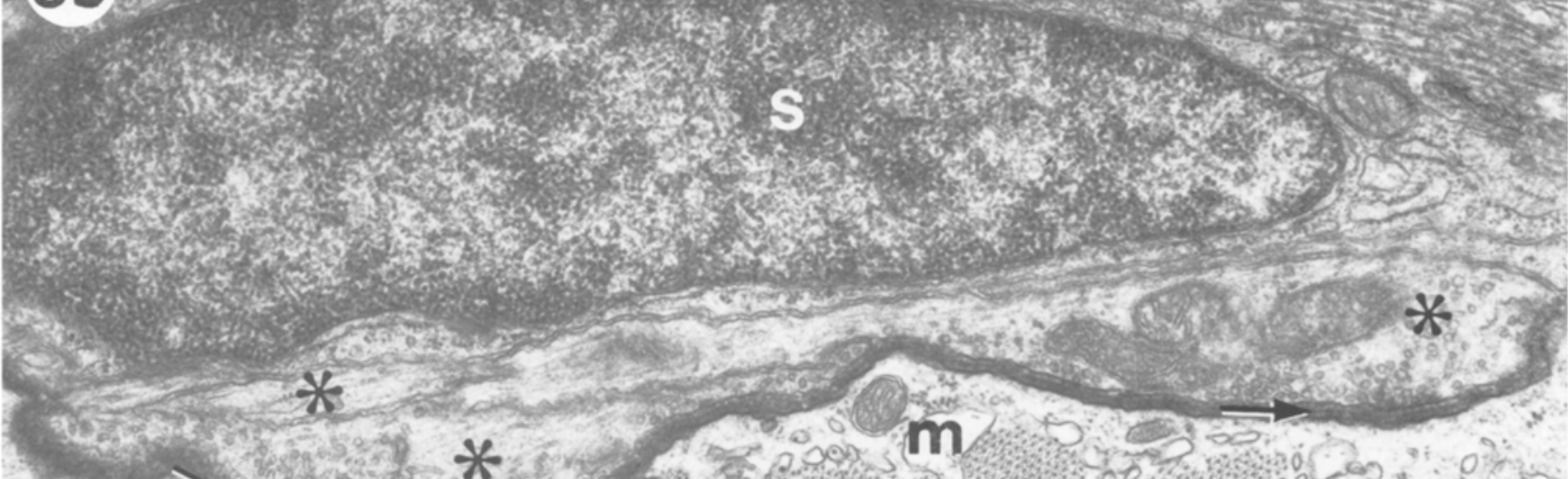

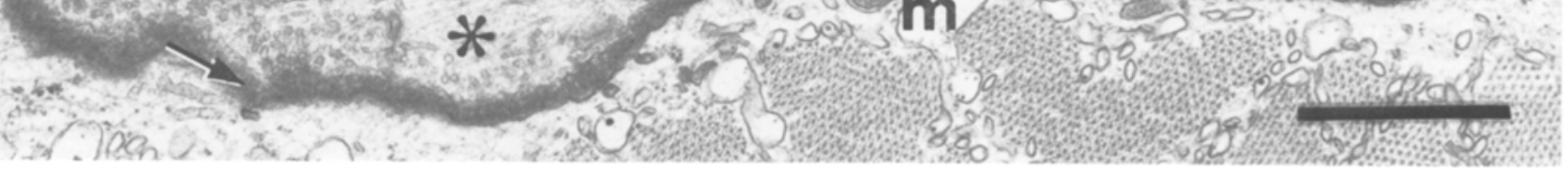

\section{6}

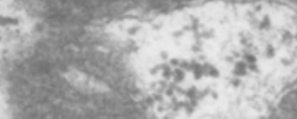

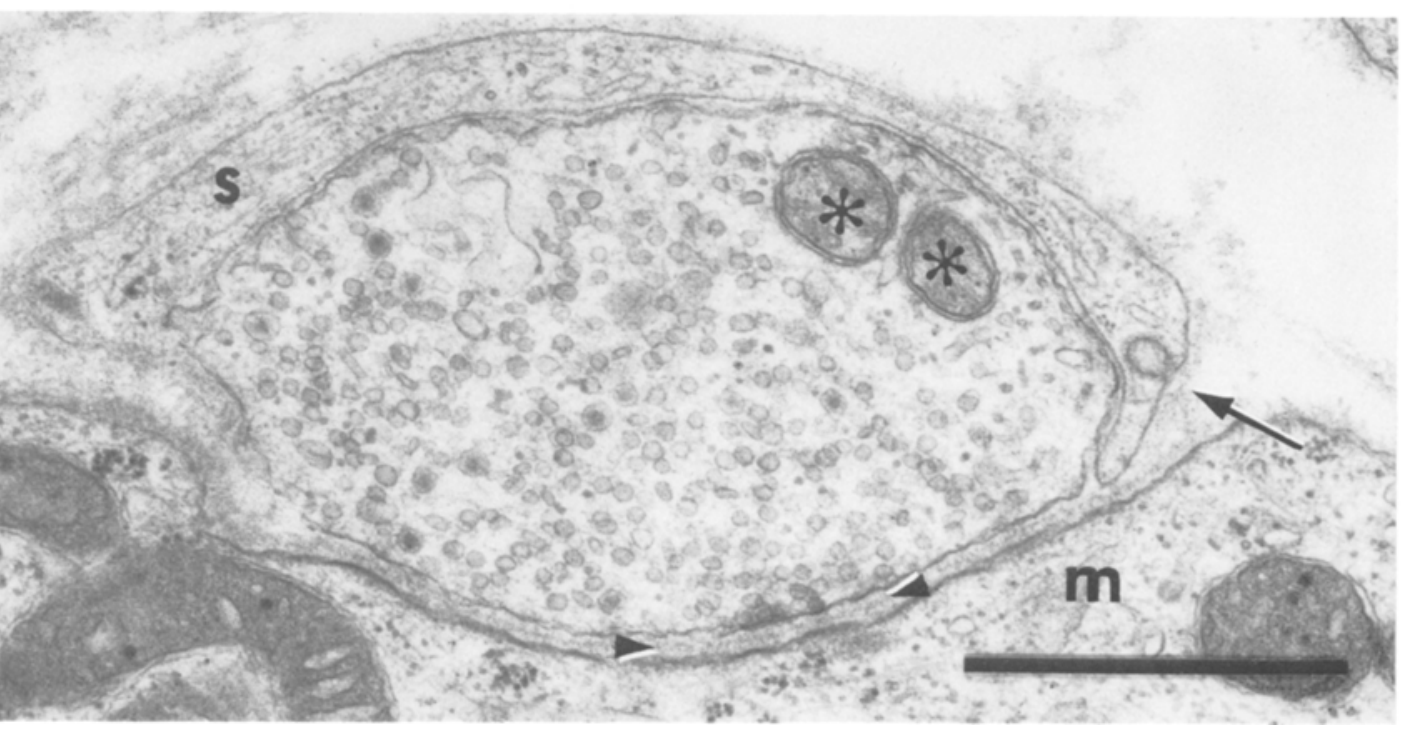


were found even at 107 days. At 13 and 31 days, there were immature-appearing terminals, as well as others that were indistinguishable from the original ones (Fig. 36), and intermediates between the two. The number of synapses increased progressively between 8 and 107 days (Fig. 37c), which corroborated our impression that there were progressively fewer uninnervated endplates over this period.

\section{QUANTITATIVE ANALYSIS OF REGENERATION}

We restricted our quantitative analysis to crushed nerves. Crushes seemed to be both more likely to provide a favourable situation for axonal regeneration and more reproducible than transections or resections, in which the width of the gap and the amount of scar tissue were difficult to control. The average number of regenerating axons was analysed in two ways; by counting the number in the distal stumps (Fig. 37a), and by expressing the number of axons in the distal and proximal stumps as a ratio (Fig. 37b). The ratio allowed us to compare the number of axons in the distal stump per axon in the proximal stump; hence it was not sensitive to inter-animal variation in the
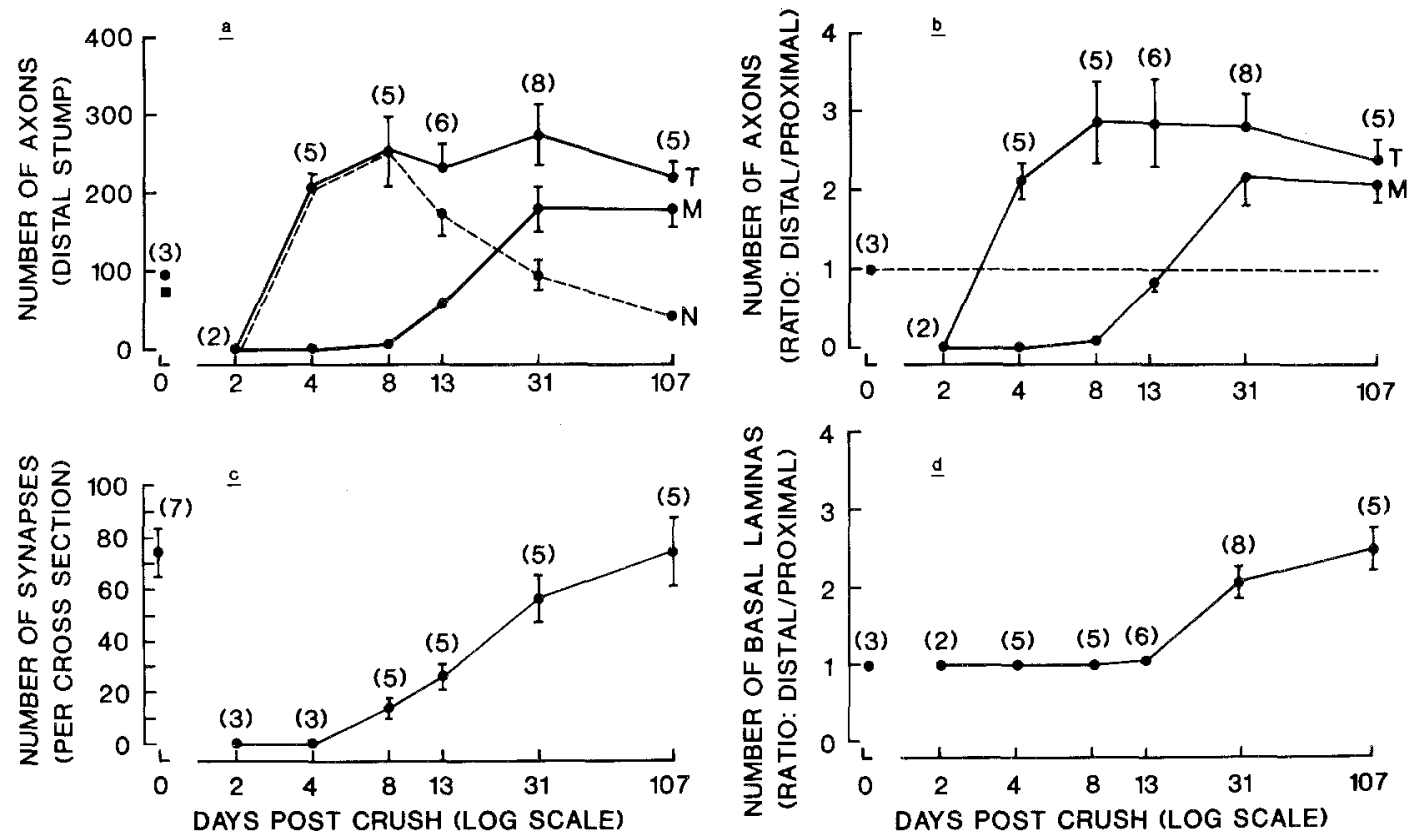

Fig. 37. Quantitative aspects of degeneration and regeneration. All points represent the mean \pm 1 S.E.M. when the latter is large enough to be illustrated. The number of animals at each time interval is given in parentheses. The values at 0 days are from unlesioned animals. (a) The number of axons in the distal stump. (b) The number of axons in the distal and proximal stumps, expressed as a ratio; the dotted line equals the value of this ratio in unlesioned nerves for both total and myelinated axons. (c) The number of synapses in a single transverse section of the superior oblique muscle. (d) The number of basal laminae in the distal and proximal stumps, expressed as a ratio. $T$, Total axons; $M$, myelinated axons; $N$, non-myelinated axons. 
number of axons in the proximal stump (Easter, 1979). Both methods gave similar, but not identical, results.

To analyse the number of axons as a ratio, it was important to show that the number of axons in the proximal stump was unchanged by the lesion, so that the ratio only reflected changes in the distal stump. Since we could identify the few degenerating myelinated axons and non-myelinated axons in the proximal stump between 2 and 31 days, we included the former, but excluded the latter, from our counts. Even at 107 days, when remyelinated and intact myelinated axons could have been confused, the number of myelinated axons was similar to that found in nerves between 2 and 31 days [mean \pm 1 S.D. $=83.2 \pm 4.1(n=5)$ and $80.8 \pm 10.5(n$ $=26$ ), respectively]. Thus, myelinated axons did not appear to be lost or gained by the proximal stumps of crushed nerves. To rule out the possibility that there were recurrent regenerating axons in the proximal stump, as have been described proximal to neuromas (Scadding \& Thomas, 1983), we also labelled one nerve with HRP 33 days after crush. Although the regenerating axons were not as straight as those in an unlesioned, labelled nerve, none was recurrent.

The number of non-myelinated axons increased between 2 and 8 days after crush and declined thereafter (Fig. 37a). The remyelination of non-myelinated axons accounted for most of this decline, as the total number of axons remained approximately constant between 8 and 31 days, when the number of remyelinated axons was increasing dramatically (Fig. 37a,b). Although some of the non-myelinated axons also appeared to degenerate (see above, ) they probably were a minority, as the distal-proximal ratio of the total number of axons (Fig. 37b) did not change significantly at any time between 8 and 107 days $(P>0.10$ for all possible pairs of days, two-sample Mann-Whitney $U$ test; Conover, 1971). The increased number of myelinated axons in the distal stump, more than $100 \%$ at both 31 and 107 days (Fig. 37b), was apparently permanent as none was observed to degenerate (see above).

We wished to learn whether the increased number of non-myelinated axons in the distal stump represented an invasion of the distal stump by an excess of sprouts from the proximal stump, as opposed to axonal branching within the distal stump itself. That the number of axons per Schwann tube was similar in the proximal and distal stumps suggested that the first possibility was correct. To rule out the second possibility, we counted all the axons in individual nerves, both at the site of crush and 250-400 $\mu \mathrm{m}$ distal to it. The number of axons in each distal stump differed from that at the site of crush by $-22,-7,-3,+12$ and $+15 \%$ at 4 days $(n=5)$, and by $-9,+7,+8$ and $+31 \%$ at 8 days after crush $(n=4)$. The slightly lower counts in the distal stump at 4 days probably indicate that some of the growth cones had not yet reached it. The slightly higher counts at 8 days are consistent with a small amount of distal branching. Since the differences in the number of axons between the site of crush and distal stump were modest in comparison to the total increase (Fig. 37b), we conclude that most of the axons in the distal stump were probably formed in the proximal stump. Furthermore, the 
similarity of the numbers of axons counted at the two locations indicates that the number of axons depended more on the individual nerve than on the exact location sampled.

At 4 and 8 days after crush, the larger Schwann tubes in the distal stump often contained more axons than the smaller ones, which sometimes contained none (Fig. 14). This observation was quantified by measuring the perimeter of each basal lamina (see above) and counting the number of axons within each of them. As summarized in Table 1 , the largest $50 \%$ of the basal laminae contained significantly more axons than the smallest 50\%. This result might either indicate that large myelinated axons in the proximal stump produced more sprouts that reached the distal stump than smaller ones did (Shawe, 1954) or that regenerating axons enlarged their Schwann tubes. Although neither possibility could be conclusively ruled out, the latter one seems unlikely since the Schwann tubes appeared to be ultrastructurally intact and their sizes tended to decrease, not increase (see above). That regenerating axons were found almost exclusively within the basal laminae in the proximal stump, at the site of crush and in the distal stump, suggests that they remained within the same basal lamina throughout the nerve, which is consistent with the first possibility.

Table 1. Results of Kolmogorov-Smirnov and $\chi^{2}$ tests.

\begin{tabular}{rlll}
\hline Animal $^{*}$ & Kolmogorov-Smirnov test ${ }^{\dagger}$ & $\chi^{2}$ test $\ddagger$ \\
\hline 1 & Unlesioned & n.s. & - \\
2 & Unlesioned & n.s. & - \\
3 & Unlesioned & n.s. & - \\
4 & 2 days & n.s. & - \\
5 & 2 days & n.s. & 0.0010 \\
6 & 4 days & n.s. & 0.0034 \\
7 & 4 days & $0.01>P$ & 0.0802 \\
8 & 4 days & n.s. & $0.0001>P$ \\
9 & 4 days & n.s. & 0.0205 \\
10 & 4 days & $0.05>P>0.01$ & 0.0278 \\
11 & 8 days & $0.05>P>0.01$ & $0.0001>P$ \\
12 & 8 days & n.s. & 0.0012 \\
13 & 8 days & n.s. & $0.0001>P$ \\
14 & 8 days & $0.01>P$ & - \\
\hline
\end{tabular}

\footnotetext{
* One nerve ( 8 days after crush) was excluded because many of its basal laminae were sectioned obliquely. The distributions for animals 3, 4, 12 and 14 are shown in Fig. 15a-d, respectively. (Days = days after crush.) $\dagger$ The Kolmogorov-Smirnov test (two-sided, large size sample, Sokal \& Rohlf, 1981) on the distribution of the perimeters of the basal laminae between the proximal and distal stumps. The probabilities $(P)$ that were greater than 0.05 are listed as not significant (n.s.).

$¥$ Results of the $\chi^{2}$ test of a $2 \times 4$ contingency table. The basal laminae in each distal stump were divided into two equal groups, the largest $50 \%$ of the perimeters and the smallest $50 \%$, and the number of axons within these basal laminae was divided into four groups $(0,1,2-3$, and 4 or more). The probability $(P)$ that the observed distribution (the number of axons in the largest $50 \%$ and smallest $50 \%$ perimeters) came from the same distribution was computed.
} 
To compare our electron microscopic counts of myelinated axons with the light microscopic counts previously reported by others (see below) more accurately, we counted the number of myelinated axons in adjacent sections of distal stumps by both light and electron microscopy. The average number of myelinated axons counted light microscopically was $97 \%$ (S.E.M. $4.7 \%, n=6$ ) of that counted electron microscopically at 13 days after crush; it was $97 \%$ (S.E.M. $2.1 \%, n=8$ ) at 31 days, and $99 \%$ (S.E.M. $0.7 \%$, $n=5)$ at 107 days. Thus, the two methods agreed well, and the accuracy of light microscopy improved as the myelin sheaths thickened.

\section{Discussion}

Sensory axons in the trochlear nerve

Some of the axons in the trochlear nerve may have been afferents from the superior oblique muscle. Putative sensory endings have been described in the extraocular muscles of teleosts (Luiten, 1979; Montgomery \& Macdonald, 1980), and single units responding to stretch have been recorded in the inferior oblique nerve (Montgomery \& Macdonald, 1980). Luiten (1979) has labelled cells in the fused ganglia of the trigeminal, facial and anterior lateral line nerves after injections of horseradish peroxidase into the superior oblique muscle, but he did not determine the pathway of their axons to the muscle. The observation that unmyelinated axons were typically found peripheral to, but not central to, the anastomoses between the trochlear nerve and supraorbital trunk suggests that they joined the trochlear nerve there. The absence of unmyelinated axons in the central portion of the trochlear and abducens (Sterling, 1977) nerves of goldfish is surprising, as unmyelinated axons have been found in the ventral roots of many vertebrates (Coggeshall, 1980), of which the trochlear and abducens nerves are said to be serial homologues (Romer \& Parsons, 1977). Thus, it is likely that the central, but not the peripheral, portion of the trochlear nerve is exclusively motor.

Degeneration in the nerve

Ramón y Cajal (1928) distinguished traumatic degeneration, in the immediate vicinity of the lesion, from Wallerian degeneration, which occurs more distally. If this distinction is significant, our observations pertain best to traumatic degeneration, as they were mainly confined to the region between $2-4 \mathrm{~mm}$ proximal and $1 \mathrm{~mm}$ distal to the lesion.

In our material, axons began to degenerate by 2 days, which is typical for peripheral nerves of vertebrates (Joseph, 1973). Claims that axotomized axons persist intact for weeks (Fisher \& Turano, 1963; Calabretta et al., 1973) probably result from the failure to distinguish unmyelinated axons from regenerating axons and glial processes (see below). The fate of the degenerating axoplasm was unclear. It may have diffused into extracellular space (Weddell \& Glees, 1941; Schlaepfer \& Hasler, 1979) or have been phagocytosed by Schwann cells (Singer \& Steinberg, 1972; Matthews, 1973; Chu-Wang \& Oppenheim, 1978). Unlike Singer \& Steinberg (1972), however, we could usually find the axolemma except when the axon was electron-lucent (Fig. 9), which may have been an advanced state of degeneration. 
We found myelin debris within both Schwann cells and macrophages. The distribution of these macrophages suggests that they entered the Schwann tubes and phagocytosed myelin, then left via the perineurium. These macrophages could have either been blood-borne (Olsson \& Sjöstrand, 1969; Berner et al., 1973; Oehmichen \& Torvik, 1976) or endogenous, as they were found around and within unlesioned nerves (Oldfors, 1980).

Although there is widespread agreement that Schwann cells initially contain the myelin debris, the role of macrophages is disputed. Neglecting for the moment the uncertainty between traumatic and Wallerian degeneration, our interpretation is consistent with the several classic reports that macrophages invade Schwann tubes (Ramón y Cajal, 1928; Speidel, 1935; Holmes \& Young, 1942), which has occasionally been found electron microscopically (Thomas, 1964; Gibson, 1979). Our interpretation differs, however, from many previous electron microscopic studies that either fail to mention the presence of macrophages containing myelin debris or say that they are scarce (Barton, 1962; Fisher \& Turano, 1963; Lee, 1963; Satinsky et al., 1964; Cravioto, 1969; Calabretta et al., 1973; Weinberg \& Spencer, 1978) or that even deny that macrophages phagocytose myelin (Nathaniel \& Pease, 1963a; Holtzman \& Novikoff, 1965; Singer \& Steinberg, 1972). Macrophages that contain myelin debris and that are outside of the Schwann tubes have been interpreted either as macrophages that have phagocytosed extra-tubal myelin (Ohmi, 1961) or myelin that was transferred to them by Schwann cells (O'Daly \& Imaeda, 1967; Williams \& Hall, 1971), or as transformed Schwann cells that have migrated out of the Schwann tubes (Weiss \& Wang, 1945; Morris et al., 1972). In summary, whether macrophages participate in Wallerian degeneration to the same extent as they do in traumatic degeneration cannot be determined from the conflicting literature, as they have not been consistently recognized even in traumatic degeneration. Since mammalian Schwann cells and macrophages are difficult to distinguish morphologically (Ballin \& Thomas, 1969), the resolution of this problem may require a new approach, such as cell-specific markers.

The fate of debris-laden macrophages has also been disputed. Earlier studies (Ramón y Cajal, 1928; Holmes \& Young, 1942) suggested that they left via endoneurial blood vessels. In agreement with the present report, O'Daly \& Imaeda (1967) were the first to observe macrophages passing through the perineurium and aggregating around epineurial blood vessels, but later workers (Williams \& Hall, 1971; Gibson, 1979) were unable to confirm this. One possible reason for this discrepancy is that the nerves studied by O'Daly \& Imaeda (1967) were small, like the trochlear, which frequently lacked any blood vessels, whereas the other workers have studied much larger nerves that probably contained many endoneurial blood vessels. Perhaps macrophages migrate through the endoneurial blood vessels of large nerves, whereas in small nerves, a transperineurial route is necessary.

Identification of non-myelinated axons

In order to count the non-myelinated axons, we had to distinguish them from intact 
myelinated and unmyelinated axons, and processes of other cells, especially Schwann cells. This was possible because most of the original axons of the distal stump had begun to degenerate by 2 days, the earliest time that we observed any non-myelinated axons in the distal stump, and the unique ultrastructure of the non-myelinated axons was easily distinguished from that of intact axons.

That Schwann cell processes in degenerating autonomic nerves ultrastructurally resemble unmyelinated axons has been noted by many investigators (see Payer, 1979 for references), and Payer (1979) has shown that both of them often have similar electron density, longitudinally orientated microtubules and $10 \mathrm{~nm}$ filaments. A similar confusion between Schwann cell processes and non-myelinated axons has apparently occurred in other studies of axonal regeneration in peripheral nerves (Causey \& Hoffman, 1955; Lee, 1963, Figs. 8-9, 13; Nathaniel \& Pease, 1963b, Figs. 7-9). These investigators used osmium as the primary fixative; nerves prefixed in aldehydes show better preservation so that axons can be distinguished from Schwann cell processes because the Schwann cell filaments are tightly packed and are not interconnected by the prominent wispy material that cross-links neurofilaments (Fig. 22; see also Politis \& Spencer, 1981; Tohyama et al., 1983). Future studies could also take advantage of the immunological differences between neurofilaments and vimentin, which appears to be the principal intermediate filament of Schwann cells (Autilio-Gambetti et al., 1982).

Quantitative aspects of regeneration

We found that the total number of axons in the distal stump reached a maximum at 8 days after crush (an average increase of 189\%; Fig. 37b). Although several light microscopic studies have reported similar increases in the distal stumps of crushed nerves, the number of axons peaked much later. For example, Shawe (1954) found an increase of $110 \%$ at 50 days (nerve to the medial head of the gastrocnemius in rabbits), and Evans \& Murray (1956) illustrated an increase of more than $200 \%$ at 200 days (motor bundle of the recurrent laryngeal nerve in rabbits). It is surprising that axonal regeneration of goldfish should appear to be so much more rapid than in mammals, since the rate of axonal outgrowth in mammalian peripheral nerves $-3-4 \mathrm{~mm} /$ day (Grafstein \& McQuarrie, 1978) - is fast enough that all of the axons could have grown the $10 \mathrm{~mm}$ to the site sampled within a few days. We suggest that light microscopic counts underestimate the number of axons early in regeneration and, therefore, give an erroneous impression of the time course.

There are additional reasons for believing that previous reports (Shawe, 1954; Guth, 1956) have underestimated the total number of axons, at least early in regeneration. Silver stains, the conventional technique for staining axons, are notoriously capricious; the number of axons that are stained even depends on the particular protocol (Shawe, 1954). Many axons, especially in developing and regenerating nerves, are not myelinated and are smaller than $0.5 \mu \mathrm{m}$ in diameter (Hughes \& Egar, 1972; Bray \& Aguayo, 1974), the lower limit that Shawe (1954) could resolve. Thus each 'axon' seen light microscopically may correspond electron microscopically to an entire bundle of 
them in both mature and developing nerves (Gasser, 1955; Hughes \& Egar, 1972). Although the amount by which light microscopic counts underestimate the total number of regenerating axons is unknown, it may be by as much as a factor of 2-5 in developing nerves [compare counts in Hughes (1965) Fig. 8 to Hughes \& Egar (1972) Fig. 6]. Whereas counts of myelin-stained axons are more accurate (see above), they miss the non-myelinated axons, and would therefore give an inaccurate account of the total number. Exact counts of axons must be made electron microscopically.

In the present study, the number of myelinated axons in the distal stump increased by $112 \%$ at 107 days after crush (Fig. 37b). This is a much larger increase than has been reported in any other vertebrate peripheral nerve after a similar lesion. Although Mark \& Marotte (1972) found a similar increase in the trochlear nerve of the congeneric crucian carp (C. carassius), they sectioned several nerves intracranially, so that regenerating axons could have entered inappropriate distal stumps. Rotshenker \& McMahan (1976) found a 46\% increase distal to the crush in the nerves to the cutaneous pectoris muscle of Rana pipiens at 7 months. The number of myelinated axons $10 \mathrm{~mm}$ distal to a crush has been determined in several mammalian nerves. After 100 days, this number had returned to normal in the peroneal (Gutmann \& Sanders, 1943) and the sural (Quilliam, 1958) nerves of rabbits, or increased by $10 \%$ (nerve to the medial head of the gastrocnemius in rabbits, Shawe, 1954), 15\% (nerve to the medial head of the gastrocnemius in rats, Mira, 1976), or 60\% (motor bundle of the recurrent laryngeal nerve in rabbits, Evans \& Murray, 1956). A 24\% increase has been found 100 days after a local freeze, which like crushing, preserves the continuity of the Schwann tubes (nerve to the medial head of the gastrocnemius in rats, Mira, 1977). Because our light and electron microscopic counts of myelinated axons differed by less than $5 \%$, and because some of the above workers even used methods very similar to ours (Rotshenker \& McMahan, 1976; Mira, 1976, 1977), differences greater than 10\% between the above nerves are likely to be real. We conclude that the number of remyelinated axons in the trochlear nerve is higher than in the other nerves that have been studied, but that the reason remains obscure.

Role of basal laminae in regeneration

We have shown that all of the basal laminae persisted in the distal stump of the trochlear nerve during the first 2 weeks after crush and that their perimeters were about the same size or slightly smaller than those in the corresponding proximal stumps. These observations, together with those on the ultrastructural integrity of the basal laminae, favour the idea that the perimeter of each basal lamina remains roughly constant early in degeneration. That the basal laminae in some of the distal stumps were significantly smaller than those in the proximal stumps was not unexpected, as the shrinkage of Schwann tubes in lesioned nerves is a well-described phenomenon (Holmes \& Young, 1942; Sunderland \& Bradley, 1950; Weinberg \& Spencer, 1978).

We confirmed earlier reports that almost all of the non-myelinated axons are found within the Schwann tubes of the distal stump, even after nerve transection (Ramón y 
Cajal, 1928; Weddell, 1942; Holmes \& Young, 1942; Shawe, 1954; Ide, 1983). How this occurs has been a matter of controversy. Ramón y Cajal (1928) suggested that the Schwann cells in the distal stump elaborate chemotactic factors that attract regenerating axons to the Schwann tubes, but Weiss failed to confirm this experimentally (Weiss, 1934; Weiss \& Taylor, 1944). More recent investigators have found that sensory neurites in vitro orientate towards higher concentrations of nerve growth factor (Letourneau, 1982), which is synthesized by non-neuronal cells in vitro (Varon \& Bunge, 1978), and that regenerating axons seem to be attracted to nerve-stumps (Politis et al., 1982). On the other hand, a chemotactic factor for motor axons has not been identified, and even if it exists, it is not confined to motor nerves or it is not required by regenerating motor axons, as motor axons will erroneously regenerate within sensory nerves (Watrous, 1940; Inberg, 1949). There is no evidence that regenerating axons selectively reinnervate sub-populations of the Schwann tubes in the distal stump.

Weiss $(1934,1941)$ championed the view that the physical environment solely determined the pathway of regenerating axons: they were 'trapped' by the Schwann tubes and outgrowing Schwann cells of the distal stump, and 'blocked' from going elsewhere (Weiss \& Campbell, 1944). That regenerating axons appear to be blocked by obstacles has frequently been reported (Ramón y Cajal, 1928; Speidel, 1935; Pollard \& Fitzpatrick, 1973a,b), but none of these observations adequately explains why regenerating axons are not found in the endoneurial space around the Schwann tubes. We suggest the reason for this is that growth cones preferentially adhere to the inner surface of the basal laminae, which constitute a large surface area in the distal stump, just as axons in vitro elongate preferentially on the most adhesive available substrate (Letourneau, 1975b; Collins \& Garrett, 1980). This explanation accounts for a number of observations:

1. That neuritic outgrowth in vitro is promoted by substrates containing laminin, fibronectin, type IV collagen or heparan sulphate, which are components of basal laminae (Akers et al., 1981; Lander et al., 1982; Vlodavsky et al., 1982; Rogers et al., 1983). The basal laminae of Schwann cells have been shown to contain laminin, fibronectin and type IV collagen, as well as type V collagen and entactin, whose neuritic-promoting properties are unknown (Sanes \& Cheney, 1982; Cornbrooks, 1983; Bunge, personal communication).

2. That growth cones are always in contact with the inner surface of the basal laminae. We interpret this consistent association, and especially the flattened shape of some of the growth cones (which to our knowledge has not been previously described in regenerating nerves), as indicating a strong adhesion to the basal lamina (Letourneau, 1975a). Strong adhesion to the basal lamina also explains why axons regenerate about three times faster within the Schwarin tubes than outside them (Williams, 1930), as axonal elongation in vitro is faster on more adhesive substrates (Letourneau, 1975a).

3. That the success of axonal regeneration in allografts and autografts correlates with the ultrastructural integrity of the basal laminae (Pollard \& Fitzpatrick, 1973a, b). Thus, both the shrinkage of basal laminae and the deposition of collagen fibres on their inner 
surface (see above) could account for the impaired axonal regeneration found in chronically denervated peripheral nerves (Holmes \& Young, 1942).

4. That better functional restoration is observed after crush than after transection or resection. As the basal laminae remain intact at the site of crush (Ramón y Cajal, 1928; Haftek \& Thomas, 1968; present study), growth cones are guided to their appropriate targets (Horch, 1979; Westerfield \& Powell, 1983; Yu \& Yu, 1983). After transection or resection, however, growth cones enter inappropriate Schwann tubes (Ramón y Cajal, 1928) which misdirect them to inappropriate targets (Horch, 1979; Brushart \& Mesulam, 1980; Mizuno et al., 1980; Westerfield \& Powell, 1983). The guidance of growth cones by basal laminae also explains why regenerating axons always branch at the branchpoints of Schwann tubes (Ramón y Cajal, 1928; Williams, 1930; Speidel, 1935; Glees, 1943).

5. That nerve grafts from the P.N.S., but not the C.N.S., enable C.N.S. axons to regenerate (Aguayo et al., 1981). Perhaps the relevant feature of 'glial environment' in the P.N.S. grafts is the basal lamina of the Schwann cell, which, as is well known, does not surround any glial cell of the C.N.S.

In summary, that axons regenerate within Schwann tubes has long been appreciated, but the respective roles of the Schwann cells and the basal laminae have not been well defined. That axonal regeneration occurs within the Schwann tubes after irradiation (Pollard \& Fitzpatrick, 1973b) or freezing (Edgington et al., 1980; Ide, 1983), treatments that kill Schwann cells but spare basal laminae, indicates that the basal laminae are sufficient. We suggest that the adhesivity of the basal laminae is the relevant feature for the growth cones.

Axonal development and regeneration in the P.N.S. compared

As axonal regeneration has often been used as a model of axonal development, it is important to compare the two with respect to the present study. First, the substrates along which the growth cones of regenerating nerves travel (Schwann cells and their basal laminae) are not found at the tips of developing nerves (Prestige \& Wilson, 1980; Al-Ghaith \& Lewis, 1982). Rather, the most distal growth cones have been seen to be associated with mesenchymal cells (Al-Ghaith \& Lewis, 1982) and the basal lamina of the epidermis (Roberts \& Taylor, 1982).

Secondly, in the distal stumps of regenerating nerves, the initial number of axons often exceeds the number that ultimately remains (Shawe, 1954; Bray \& Aguayo, 1974; Ehrlich \& Mark, 1977; cf. Evans \& Murray, 1956). The observation that the number of remyelinated axons does not decline with time (Gutmann \& Sanders, 1943; Evans \& Murray, 1956; Mira, 1976, 1977; present study), and the lack of unequivocal examples of degenerating remyelinated axons, indicate that non-myelinated, but not remyelinated, axons degenerate. Similarly, in birds and amphibians, electron microscopic counts have conclusively shown that about $70 \%$ of the motor axons disappear during the period of motor neuron cell death (Prestige \& Wilson, 1974; Chu-Wang \& Oppenheim, 1978; Boydston \& Sohal, 1980), but few, if any, myelinated axons are lost (Hughes \& Egar, 
1972; Prestige \& Wilson, 1974). Since myelinated axons are not seen in avian or mammalian embryos until well after the peak of cell death (Webster, 1971; Chu-Wang \& Oppenheim, 1978; Sohal \& Weidman, 1978; Lance-Jones, 1982), the degenerating myelinated axons found in young animals seem to be an unrelated phenomenon (Reier \& Hughes, 1972; Chu-Wang \& Oppenheim, 1978; Sohal \& Weidman, 1978). In summary, myelinated axons seem to be preferentially maintained in both developing and regenerating nerves. And although cell death probably causes the loss of axons during development, the loss of axons in the distal stump of the trochlear nerve occurs without it, as the number of axons in the proximal stump remains constant.

Thirdly, in both developing and regenerating nerves, multiple axons and Schwann cells share a common basal lamina. As Schwann cells at the margin of the group become exclusively associated with a single axon (usually the largest one: Evans \& Murray, 1956; Nathaniel \& Pease, 1963b; Matthews, 1968; Hughes \& Egar, 1972; Webster et al., 1973; present study), they separate from the group, acquire their own basal lamina and myelinate the axon (Holmes \& Young, 1942; Morris et al., 1972; Webster et al., 1973; present study). An interesting difference in this regard is that when regenerating peripheral nerves are deprived of a target, many of the axons still remyelinate (Weiss et al., 1945; Aitken et al., 1947; Aitken, 1949; Evans \& Murray, 1956), whereas in developing nerves, motor axons fail to myelinate after removal of their target muscle (Prestige \& Wilson, 1974; Boydston \& Sohal, 1980). This difference is intriguing as Schwann cells require axonal contact to form both myelin sheaths and basal laminae (Aguayo et al., 1976; Weinberg and Spencer, 1976; Bunge et al., 1982).

Regeneration in the P.N.S. and the anamniotic C.N.S. compared It is commonly believed that axons in the C.N.S. of anamniotic vertebrates are able to regenerate far better than their mammalian counterparts. This has been most extensively studied in the optic nerve, where, in contrast to the transient abortive sprouting found in mammals (Richardson et al., 1982), axonal regeneration is robust. It has been examined ultrastructurally in both larval and adult anurans (Reier \& Webster, 1974; Scott \& Foote, 1981; Bohn et al., 1982), adult urodeles (Turner \& Singer, 1974; Stensaas \& Feringa, 1977), and adult teleosts (Murray, 1976, 1982; Lanners \& Grafstein, 1980). Since the present report is one of the first ultrastructural studies of regeneration in a non-mammalian peripheral nerve, we have evaluated the claim that axonal regeneration in the anamniotic optic nerve is similar to that in the peripheral nervous system (Bohn $e t$ al., 1982; Stelzner, 1982).

The entire degenerating distal stump of the amphibian optic nerve has been likened to a single Schwann tube (Bohn et al., 1982). The nerve is surrounded by a basal lamina, which remains intact after crushing or freezing and appears to keep regenerating axons within the distal stump (Stensaas \& Feringa, 1977). Regenerating axons are found in fascicles, typically near the pial surface, and growth cones are found at the margin of these fascicles (Stensaas \& Feringa, 1977; Bohn et al., 1982). Whether regenerating axons follow channels among the glia (Reier \& Webster, 1974; Murray, 1976; Bohn et al., 1982; 
Stelzner, 1982) or degenerating myelinated axons (Turner \& Singer, 1974; Stensaas \& Feringa, 1977) has been disputed (Lanners \& Grafstein, 1980).

Regenerating optic axons are disordered distal to a crush (Fawcett \& Gaze, 1981), and many of them project to inappropriate targets (Bohn \& Stelzner, 1981; Springer, 1981). Even axons that form appropriate connections often take aberrant routes (Meyer, 1980; Fujisawa et al., 1982; Stuermer \& Easter, 1984). Thus, in contrast to peripheral nerves, the distal stump of the optic nerve guides regenerating axons only in the grossest sense, and this guidance does not account for the precise reformation of retinotopic connections. The routes taken by regenerating axons in peripheral nerves, on the other hand, are dictated by the disposition of the Schwann tubes (see above); with the possible exception of urodeles (Grimm, 1971; Stephenson, 1979), there is no evidence that regenerating axons can form appropriate connections via aberrant routes.

Reinnervation of the superior oblique muscle

Nearly all of the axons and neuromuscular junctions in the superior oblique muscle were degenerating by 2 days. This is about 2 days faster than reported by Marotte \& Mark (1970). Their lesions were performed more centrally, which accounts for this discrepancy as the degeneration of axonal terminals is delayed by a longer distal stump (Miledi \& Slater, 1970).

We found newly formed neuromuscular junctions as early as 8 days after crush. Without the elaborate post-junctional folds found in other vertebrates, it was not possible in our material to show conclusively that regenerating axons formed synapses exclusively at the former sites of endplates (see Letinsky et al., 1976 for references), although we believe that this was, in fact, the case. Since the basal laminae of the Schwann tubes were presumably intact from the proximal stump to the endplate, regenerating axons could have followed them the entire way. As Edgington et al. (1980) have shown, the basal laminae alone are sufficient to guide regenerating axons to their former endplates. Although we found more than one axonal process by some of the endplates, whether they were polyneuronally innervated, as has been found in other vertebrates after axonal regeneration (see Rotshenker \& McMahan, 1976 for references), remains to be shown.

\section{Conclusion}

This is the first electron microscopic examination of axonal regeneration in the P.N.S. of teleosts. We have shown that the axons, Schwann cells and connective tissue of unlesioned trochlear nerves, as well as the degenerative and regenerative changes in lesioned nerves, are mostly similar to those described in the peripheral nerves of other vertebrates. To review, axons and their myelin sheaths degenerate in the distal nerve stump after a lesion, but the Schwann cells and their basal laminae persist. Even after transection of the nerve, axons regenerate almost exclusively within these basal laminae, which, we suggest, provide an adhesive substrate that the growth cones of the 
regenerating axons follow. If muscles are selectively reinnervated after nerve transection in teleosts (Mark, 1965; Sperry \& Arora, 1965), then our results imply that regenerating motor axons can select the Schwann tubes of the distal stump that lead to the appropriate muscle. The selective reinnervation of Schwann tubes would be a remarkable example of neuronal specificity, and one that is not found in other vertebrates (except after nerve crush; see above). This question was recently re-examined in the oculomotor nerve of goldfish, and the evidence suggests the contrary: the extraocular muscles are not selectively reinnervated by regenerating motor axons after nerve transection (Scherer, 1983, and in preparation). Hence, it remains to be shown whether axonal regeneration in the mature P.N.S. differs among vertebrates in any fundamental way.

\section{Acknowledgements}

We thank Drs R. P. Bunge, P. Raymond and K. W. Tosney and Mr J. Fetcho for comments on the manuscript, Dr D. Baic for help with the electron microscopy, Dr A. Rusoff for help with the histochemistry, Ms M. Coffey for statistical advice, and Ms D. Scherer for drafting the figures. This work was supported by research grant EY00168 to SSE and training grant EY07122 to SSS. SSS is a member of the Medical Scientist Training Program.

\section{References}

AGUAYO, A. J., DAVID, S. \& BRAY, G. M. (1981) Influence of the glial environment on the elongation of axons after injury: transplantation studies in adult rodents. Journal of Experimental Biology 95, 231-40.

AGUAYO, A. J., EPPS, J., CHARRON, L. \& BRAY, G. M. (1976) Multipotentiality of Schwann cells in cross-anastomosed and grafted myelinated nerves: quantitative microscopy and radioautography. Brain Research 104, 1-20.

AITKEN, J. T. (1949) The effect of peripheral connections on the maturation of regenerating nerve fibres. Journal of Anatomy 83, 32-43.

AITKEN, J. T., SHARMAN, M. \& YOUNG, J. Z. (1947) Maturation of regenerating nerve fibres with various terminal connexions. Journal of Anatomy 81, 1-22.

AKERS, R. M., MOSHER, D. F. \& LILIEN, J. E. (1981) Promotion of retinal neurite outgrowth by substratum-bound fibronectin. Developmental Biology 86, 179-88.

AKERT, K., SANDRI, C., WEIBEL, E. R., PEPER, K. \& MOOR, H. (1976) The fine structure of the perineural endothelium. Cell and Tissue Research 165, 281-95.

AL-GHAITH, L. K. \& LEWIS, J. H. (1982) Pioneer growth cones in virgin mesenchyme: an electron-microscope study in the developing chick wing. Journal of Embryology and Experimental Morphology 68, 149-60.

AUtilio-GAMBETti, L., SiPPle, J., SUdilovsky, O. \& GAMBETti, P. (1982) Intermediate filaments of Schwann cells. Journal of Neurochemistry 38, 774-80.

BALLIN, R. H. M. \& THOMAS, P. K. (1969) Electron microscope observations on demyelination and remyelination in experimental allergic neuritis. II. Remyelination. Journal of the Neurological Sciences 8, 225-37. 
BARBER, D. L., WESTERMAN, J. E. M. \& White, M. G. (1981) The blood cells of the Antarctic icefish Chaenocephalus aceratus Lonnberg: light and electron microscopic observations. Journal of Fish Biology 19, 11-28.

BARTON, A. A. (1962) An electron microscopic study of degeneration and regeneration of nerve. Brain 85, 799-808.

BERGER, B. (1971) Etude ultrastructurale de la dégénerescence Wallérienne experimentale d'un nerf entierement amyelinique: le nerf olfactif. I. Modications axonales. Journal of Ultrastructure Research 37, 105-18.

BERNER, A., TORVIK, A . \& STENWIG, A. E. (1973) Origin of macrophages in traumatic lesions and Wallerian degeneration in peripheral nerves. Acta neuropathologica 25, 228-36.

BITTNER, G. D. \& JOHNSON, A. L. (1974) Degeneration and regeneration in crustacean peripheral nerves. Journal of Comparative Physiology 89, 1-21.

BLOOM, W. \& FAWCETT, D. W. (1975) A Textbook of Histology. Philadelphia: Saunders.

BLÜMCKE, S., NIEDORF, H. R. \& RODE, J. (1966) Axoplasmic alterations in the proximal and distal stumps of transected nerves. Acta neuropathologica 7, 44-61.

BOHN, R. C., REIER, P. J. \& SOURBEER, E. B. (1982) Axonal interactions with connective tissue and glial substrata during optic nerve regeneration in Xenopus larvae and adults. American Journal of Anatomy 165, 397-419.

BOHN, R. C. \& STELZNER, D. J. (1981) The aberrant retino-retinal projection during optic nerve regeneration in the frog. I. Time course of formation and cells of origin. Journal of Comparative Neurology 196, 605-20.

BOYDSTON, W. R. \& SOHAL, G. S. (1980) Intact peripheral target essential for branching of developing nerve fibers. Experimental Neurology 70, 173-8.

BRAY, G. M. \& AGUAYO, A. J. (1974) Regeneration of peripheral unmyelinated nerves. Fate of axonal sprouts which develop after injury. Journal of Anatomy 117, 517-29.

BRUSHART, T. M. \& MESULAM, M-M. (1980) Alternation in connections between muscle and anterior horn motoneurons after peripheral nerve repair. Science 208, 603-5.

BUNGE, M..B. (1973) Fine structure of nerve fibers and growth cones of isolated sympathetic neurons in culture. Journal of Cell Biology 56, 713-35.

BUNGE, M. B., WILLIAMS, A. K. \& WOOD, P. M. (1982) Neuron-Schwann cell interaction in basal lamina formation. Developmental Biology 92, 449-60.

CALABRETTA, A. M., MUNGER, B. L. \& GRAHAM, W. P. (1973) The ultrastructure of degenerating rat sciatic nerves. Journal of Surgical Research 14, 465-71.

CANNON, M. S., MOLLENHAUER, H. H., EURELl, T. E., LEWIS, D. H., CANNON, A. M. \& TOMPKINS, C. (1980) An ultrastructural study of the leukocytes of the channel catfish. Ictalurus punctatus. Journal of Morphology 164, 1-23.

CAUSEY, G. \& HOFFMAN, H. (1955) Axon sprouting in partially deneurotized nerves. Brain 78, 661-8.

CHU-WANG, I.-W. \& OPPENHEIM, R. W. (1978) Cell death of motoneurons in the chick embryo spinal cord. II. A quantitative and qualitative analysis of degeneration in the ventral root, including evidence for axon outgrowth and limb reinnervation prior to cell death. Journal of Comparative Neurology 177, 59-86.

COGGESHALL, R. E. (1980) Law of separation of function of spinal roots. Physiological Reviews 60, 716-55.

COLLINS, F. \& GARRETT, J. E. (1980) Elongating nerve fibers are guided by a pathway of material released from embryonic nonneuronal cells. Proceedings of the National Academy of Sciences USA 77, 6626-8.

CONOVER, W. J. (1971) Practical Nonparametric Statistics. New York: Wiley.

COOK, R. D., GHETTI, B. \& WISNIEWS KI, H. M. (1974) The pattern of Wallerian degeneration in the optic nerve of newborn kittens: an ultrastructural study. Brain Research 75, 261-75. 
CORNBROOKS, C. (1983) Expression and distribution of entactin in extracellular matrix of adult rat peripheral nerve and peripheral nerve cells in culture. Society for Neuroscience Abstracts 9, 346.

CRAVIOTO, H. (1969) Wallerian degeneration: ultrastructural and histochemical studies. Bulletin of the Los Angeles Neurological Society 34, 233-53.

DAVEY, D. F., MARK, R. F., MAROTTE, L. R. \& PROSKE, U. (1975) Structure and innervation of extraocular muscles of Carassius. Journal of Anatomy 120, 131-47.

DYCK, P. J. \& HOPKINS, A. P. (1972) Electron microscopic observations on degeneration and regeneration of unmyelinated fibers. Brain 95, 123-34.

EASTER JR, S. S. (1979) The growth and development of the superior oblique muscle and trochlear nerve in juvenile and adult goldfish. Anatomical Record 195, 683-98.

EASTER JR, S. S., RUSOFF, A. C. \& KISH, P. E. (1981) The growth and organization of the optic nerve and tract in juvenile and adult goldfish. Journal of Neuroscience 1, 799-811.

EDGINGTON, D. R., KUFFLER, D. P. \& MCMAHON, U. J. (1980) Extracellular structures at the neuromuscular junction direct the growth of regenerating axons. Society for Neuroscience Abstracts 6, 92.

EHRLICH, D. \& MARK, R. F. (1977) Fiber counts of regenerating peripheral nerves in axolotls and the effect of metamorphosis. Journal of Comparative Neurology 174, 306-16.

ELLIOT, E. J. \& MULLER, K. J. (1981) Long term survival of glial segments during nerve regeneration in the leech. Brain Research 218, 99-113.

ELLIS, A. E. (1977) The leukocytes of fish: a review. Journal of Fish Biology 11, 453-91.

ESTABLE, C., ACOSTA-FERREIRA, W. \& SOTELO, J. R. (1957) An electron microscope study of regenerating nerve fibers. Zeitschrift für Zellforschung und mikroskopische Anatomie 46, 387-99.

EVANS, D. H. L. \& MURRAY, J. G. (1956) A study of regeneration in a motor nerve with a unimodal fiber diameter distribution. Anatomical Record 126, 311-33.

FAWCETT, J. W. \& GAZE, R. M. (1981) The organization of regenerating axons in the Xenopus optic nerve. Brain Research 229, 487-90.

FERGUSON, H.W. (1976) The ultrastructure of plaice (Pleuronectes platessa) leucocytes. Journal of Fish Biology 8, 139-42.

FISHER, E. R. \& TURANO, A. (1963) Schwann cells in Wallerian degeneration. Archives of Pathology 75, 517-27.

FRIEDE, R. L. \& BISCHHAUSEN, R. (1980) The fine structure of transected nerve fibers in subserial sections. Journal of Neurological Sciences 44, 181-203.

FUJISAWA, H., TANI, M., WATANABE, K. \& IBATA, Y. (1982) Branching of regenerating retinal axons and preferential selection of appropriate branches for specific neuronal connection in the newt. Developmental Biology 90, 43-57.

GASSER, H. S. (1955) Properties of dorsal root unmyelinated fibers on the two sides of the ganglion. Journal of General Physiology 38, 709-28.

GAZE, R. M. (1970) The Formation of Nerve Connections, pp. 8-75. London: Academic Press.

GIBSON, J. D. (1979) The origin of the neural macrophage: a quantitative ultrastructural study of cell population changes during Wallerian degeneration. Journal of Anatomy 129, 1-19.

GLEES, P. (1943) Observations on the structure of the connective tissue sheaths of cutaneous nerves. Journal of Anatomy 77, 153-9.

GRAFSTEIN, B. \& MC QUARRIE, I. G. (1978) Role of the nerve cell body in axonal regeneration. In Neuronal Plasticity (edited by COTMAN, C. W.), pp. 155-95. New York: Raven Press.

GRIMM, L. (1971) An evaluation of myotypic respecification in axolotls. Joumal of Experimental Zoology 178, 479-96.

GUTH, L. (1956) Regeneration in the mammalial peripheral nervous system. Physiological Reviews $36,441-78$.

GUTMANN, E. \& SANDERS, F. K. (1943) Recovery of fibre numbers and diameters in the regeneration of peripheral nerves. Journal of Physiology 101, 489-518. 
GUTMANN, E. \& YOUNG, J. Z. (1944) The reinnervation of muscle after various periods of atrophy. Journal of Anatomy 78, 15-43.

HAFTEK, J. \& THOMAS, P. K. (1968) Electron-microscope observations on the effects of localized crush injuries on the connective tissues of the peripheral nerve. Journal of Anatomy 103, $233-43$.

HALL, S. M. (1973) Some aspects of remyelination after demyelination produced by intraneural injection of lysophosphatidyl choline. Journal of Cell Science 13, 461-77.

HERRICK, C. J. (1899) The cranial nerves and first spinal nerves of Menidia; a contribution upon the nerve components of bony fishes. Journal of Comparative Neurology 9, 153-455.

HOLMES, W. \& YOUNG, J. Z. (1942) Nerve regeneration after immediate and delayed suture. Journal of Anatomy 77, 63-97.

HOLTZMAN, E. NOVIKOFF, A. B. (1965) Lysosomes in the rat sciatic nerve following crush. Journal of Cell Biology 27, 651-69.

HORCH, K. W. (1979) Guidance of regrowing sensory axons after cutaneous nerve lesions in the cat. Journal of Neurophysiology 42, 1437-49.

HUGHES, A. F. (1965) A quantitative study on the development of the nerves in the hindlimb of Elentherodactylus martinensis. Journal of Embryology and Experimental Morphology 13, 9-34.

HUGHES, A. \& EGAR, M. (1972) The innervation of the hindlimb of Elentherodactylus martinicensis: further comparison of cell and fiber numbers during development. Joumal of Embryology and Experimental Morphology 27, 389-412.

IDE, C. (1983) Nerve regeneration and Schwann cell basal lamina: observations of long-term regeneration. Archivum Histologicum Japonicum 46, 243-57.

INBERG, K. R. (1949) Regeneration of motor and sensory fibres in the sciatic nerve and in the suralis nerve of the cat. Acta physiologica scandinavica 18, 308-23.

JOSEPH, B. S. (1973) Somatofugal events in Wallerian degeneration: a conceptual overview. Brain Research 59, 1-18.

KAPELLER, K. \& MAYOR, D. (1969) An electron microscopic study of early changes proximal to a constriction in sympathetic nerves. Proceedings of the Royal Society of London B 172, 39-51.

KARNOVSKY, M. J. (1967) The ultrastructural basis of capillary permeability studied with peroxidase as a tracer. Journal of Cell Biology 35, 213-36.

KILARSKI, W. \& BIGAJ, J. (1969) Organization and fine structure of extraocular muscle in Carassius and Rana. Zeitschrift für Zellforschung und mikroskopische Anatomie 94, 194-204.

KING, R. H. M. \& THOMAS, P. K. (1971) Electron microscopic observations on aberrant regeneration of unmyelinated axons in the vagus nerve of the rabbit. Acta neuropathologica 18, $150-9$.

KRUGER, L. \& MAXWELL, D. S. (1969) Wallerian degeneration in the optic nerve of a reptile: an electron microscopic study. American Journal of Anatomy 125, 247-70.

LANCE-JONES, C. (1982) Motoneuron cell death in the developing lumbar spinal cord of the mouse. Developmental Brain Research 4, 473-9.

LANDER, A. J., FUIII, D. K., GOSPODAROWICZ, D. \& REICHARD, L. F. (1982) Characterization of a factor that promotes neurite outgrowth-evidence linking activity to a heparan sulfate proteoglycan. Journal of Cell Biology 94, 574-85.

LANNERS, N. N. \& GRAFSTEIN, B. (1980) Early stages of axonal regeneration in the goldfish optic nerve: an electron microscopic study. Journal of Neurocytology 9, 733-51.

LEE, J. C-Y. (1963) Electron microscopy of Wallerian degeneration. Journal of Comparative Neurology $120,65-80$.

LETINSKY, M. S., FISCHBECK, K. H. \& MCMAHAN, U. J. (1976) Precision of reinnervation of original postsynaptic sites in frog muscle after nerve crush. Journal of Neurocytology 5, 691-718.

LETOURneAu, P. C. (1975a) Possible roles for cell-to-substratum adhesion in neuronal morphogenesis. Developmental Biology 44, 77-91. 
LETOURNEAU, P. C. (1975b) Cell-to-substratum adhesion and guidance of axonal elongation. Developmental Biology 44, 92-101.

LeTourneau, P. C. (1982) Nerve fiber growth and extrinsic factors. In Neuronal Development (edited by SPITZER, N. C.), pp. 213-54. New York: Plenum.

LUBIŃS KA, L. (1959) Region of transition between preserved and regenerated parts of myelinated fibers. Journal of Comparative Neurology 113, 315-25.

LUiten, P. J. M. (1979) Proprioceptive reflex connections of head musculature and the mesencephalon trigeminal nucleus in the carp. Journal of Comparative Neurology 183, 903-12.

LUITEN, P. J. M. \& DIJKSTRA-DE VLIEGER, H. P. (1978) Extraocular muscle representation in the brainstem of the carp. Journal of Comparative Neurology 179, 669-76.

MARK, R. F. (1965) Fin movements after regeneration of neuromuscular connections: an investigation of myotypic respecification. Experimental Neurology 12, 292-302.

MARK, R. F. \& MAROTTE, L. R. (1972) The mechanism of selective reinnervation of fish eye muscles. III. Functional, electrophysiological, and anatomical analysis of recovery from section of the IIIrd and IVth nerves. Brain Research 46, 131-48.

MAROTTE, L. R. \& MARK, R. F. (1970) The mechanism of selective reinnervation of fish eye muscle. II. Evidence from electron microscopy of nerve endings. Brain Research 19, 53-62.

MATSUMOTO, D. E. \& SCALIA, F. (1981) Long-term survival of centrally projecting axons in the optic nerve of the frog following destruction of the retina. Journal of Comparative Neurology 202, 135-55.

MATTHEWS, M. A. (1968) An electron microscopic study of the relationship between axon diameter and the initiation of myelin production in the peripheral nervous system. Anatomical Record 161, 337-52.

MATTHEWS, M. R. (1973) An ultrastructural study of axonal changes following constriction of the postganglionic branches of the superior cervical ganglion in the rat. Philosophical Transactions of the Royal Society of London B 264, 479-508.

MEYER, R. L. (1980) Mapping the normal and regenerating retinotectal projection of goldfish with autoradiographic methods. Journal of Comparative Neurology 189, 273-89.

MILEDI, R. \& SLATER, C. R. (1970) On the degeneration of rat neuromuscular junctions after nerve section. Journal of Physiology 207, 507-28.

MIRA, J-C. (1976) Etudes quantitatives sur la régénération des fibres nerveuses myélinisées. II. Variations du nombre et du calibre des fibres régénérées après un écrasement ou une section du nerf. Archives d'Anatomie Microscopique et de Morphologie Experimentale 65, 255-84.

MIRA, J-C. (1977) Etudes quantitatives sur la régénération des fibres nerveuses myélinisées. III. Variations du numbre et du calibre des fibres régénérées après une congélation localisée. Archives d'Anatomie Microscopique et de Morphologie Experimentale 66, 1-15.

MIRE, J. J., HENDELMAN, W. J. \& BUNGE, R. P. (1970) Observations on a transient phase of focal swelling in degenerating unmyelinated nerve fibres. Journal of Cell Biology 45, 9-22.

MIZUNO, N., UAMURA, M., MATSUDA, K., TAKENCHI, Y., KUME, M. \& MATSUSHIMA, R. (1980) Non-selective distribution of hypoglossal nerve fibers of hypoglossal section and resuture. Neuroscience Letters 19, 33-7.

MONTGOMERY, J. C. \& MaCDONALD, J. A. (1980) Stretch receptors in the eye muscles of teleost fish. Experientia 36, 1176-7.

MORRIS, J. H., HUDSON, A. R. \& WEDDELL, A. G. M. (1972) A study of degeneration and regeneration in the divided rat sciatic nerve. I-IV. Zeitschrift für Zellforschung und mikroskopische Anatomie 124, 76-203.

MURRAY, M. (1976) Regeneration of retinal axons in the goldfish optic tectum. Journal of Comparative Neurology 168, 175-96.

MURRAY, M. (1982) A quantitative study of regenerative sprouting by optic axons in goldfish. Journal of Comparative Neurology 209, 352-62. 
NATHANiEL, E. J. H. \& PEASE, D. C. (1963a) Degenerative changes in rat dorsal roots during Wallerian degeneration. Journal of Ultrastructure Research 9, 511-32.

NATHANIEL, E. J. H. \& PEASE, D. C. (1963b) Regenerative changes in rat dorsal roots following Wallerian degeneration. Journal of Ultrastructure Research 9, 533-49.

NATHANIEL, E. J. H. \& PEASE, D. C. (1963c) Collagen and basement membrane formation by Schwann cells during nerve regeneration. Journal of Ultrastructure Research 9, 550-60.

O'DALY, J. A. \& IMAEDA, T. (1967) Electron microscopic study of Wallerian degeneration in cutaneous nerves caused by mechanical injury. Laboratory Investigation 170, 744-66.

OEHMICHEN, M. \& TORVIK, A. (1976) The origin of reactive cells in retrograde and Wallerian degeneration. Cell and Tissue Research 173, 343-8.

OHMI, S. (1961) Electron microscopic study on Wallerian degeneration of the peripheral nerve. Zeitschrift für Zellforschung und mikroskopische Anatomie 54, 39-67.

OLDFORS, A. (1980) Macrophages in peripheral nerves. Acta neuropathologica 49, 43-9.

OLSSON, Y. \& SJÖSTRAND, J. (1969) Origin of macrophages in Wallerian degeneration demonstrated autoradiographically. Experimental Neurology 23, 102-12.

PAYER, A. (1979) An ultrastructural study of Schwann cell response to axonal degeneration. Journal of Comparative Neurology 183, 365-84.

POLITIS, M. J., EDERLE, K. \& SPENCER, P. S. (1982) Tropism in nerve regeneration in vivo. Attraction of regenerating axons by diffusible factors derived from cells in distal nerve stumps of transected peripheral nerves. Brain Research 253, 1-12.

POLITIS, M. J. \& SPENCER, P. S. (1981) A method to separate spatially the temporal sequence of axon-Schwann cell interaction during nerve regeneration. Journal of Neurocytology 10, 221-32.

POLLARD, J. D. \& FITZPATRICK, L. (1973a) An ultrastructural comparison of peripheral nerve allografts and autografts. Acta neuropathologica 23, 152-65.

POLLARD, J. D. \& FITZPATRICK, L. (1973b) A comparison of the effects of irradiation and immunosuppressive agents on the regeneration through peripheral nerve allografts: an ultrastructural study. Acta neuropathologica 23, 166-80.

PRESTIGE, M. C. \& WILSON, M. A. (1974) A quantitative study of the growth and development of the ventral root in normal and experimental conditions. Journal of Embryology and Experimental Morphology 32, 819-33.

PRESTIGE, M. C. \& WILSON, M. A. (1980) Growth of a limb spinal nerve: an ultrastructural study. Journal of Comparative Neurology 194, 235-66.

QUILLIAM, T. A. (1958) Growth changes in sensory fibre aggregates undergoing remyelination. Journal of Anatomy 72, 383-98.

RAMÓN Y CAJAL, S. (1928) Degeneration and Regeneration of the Nervous System (translated by MAY, R. M.). Oxford: Oxford University Press.

RAWLINS, F. A., VILLEGAS, G. M., HEDLEY-WHITE, E. T. \& UZMAN, B. G. (1972) Fine structural localization of cholesterol-1,2- ${ }^{3} \mathrm{H}$ in degenerating and regenerating mouse sciatic nerve. Journal of Cell Biology 52, 615-25.

REIER, P. J. \& HUGHES, H. (1972) Evidence for spontaneous axon degeneration during peripheral nerve maturation. American Journal of Anatomy 135, 147-52.

REIER, P. J. \& WEBSTER, H. DE F. (1974) Regeneration and remyelination of Xenopus tadpole optic nerve fibres following transection or crush. Journal of Neurocytology 3, 591-618.

REYNOLDS, E. S. (1963) The use of lead citrate at high $\mathrm{pH}$ as an electron opaque stain in electron microscopy. Joumal of Cell Biology 17, 208-12.

RICHARDSON, P. M., ISSA, V. M. K. \& SHEMIE, S. (1982) Regeneration and retrograde degeneration of axons in the rat optic nerve. Journal of Neurocytology 11, 949-66.

ROBERTS, A. \& TAYLOR, J. S. H. (1982) A scanning electron microscopic study of the development of a peripheral sensory neurite network. Journal of Embryology and Experimental Morphology 69, 237-50. 
ROGERS, S. L., LETOURNEAU, P. C., PALM, S. L., MCCARTHY, J. \& FURCHT, L. (1983) Neurite extension by peripheral and central nervous system neurons in response to substratum-bound fibronectin and laminin. Developmental Biology 98, 211-20.

ROMER, A. S. \& PARSONS, T. S. (1977) The Vertebrate Body, Philadelphia: Saunders.

ROTSHENKER, S. \& MCMAHAN. U. J. (1976) Altered pattern of innervation in frog muscle after denervation. Journal of Neurocytology 5, 719-30.

SANES, J. R. \& CHENEY, J. S. H. (1982) Laminin, fibronectin, and collagen in synaptic, and extrasynaptic portions of muscle fiber basement membrane. Journal of Cell Biology 93, $442-51$.

SATINSKY, D., PEPE, F. A. \& LIU, C. N. (1964) The neurilemma cell in peripheral nerve degeneration and regeneration. Experimental Neurology 9, 441-51.

SCADDING, J. W. \& THOMAS, P. K. (1983) Retrograde growth of myelinated fibres in experimental neuromas. Journal of Anatomy 136, 793-9.

SCHERER, S. S. (1983) Non-selectivity of axonal regeneration in the oculomotor nerve of goldfish. Society for Neuroscience Abstracts 9, 47.

SCHLAEPFER, W. W. \& HASTER, M. B. (1979) The persistence and possible externalization of axonal debris during Wallerian degeneration. Journal of Neuropathology and Experimental Neurology 38, 242-52.

SCOTT, S. A. (1977) Maintained function of foreign and appropriate junctions on reinnervated goldfish extraocular muscles. Journal of Physiology 268, 87-109.

SCOTT, T. M. \& FOOTE, J. (1981) A study of degeneration, scar formation, and regeneration after section of the optic nerve in the frog, Rana pipiens. Journal of Anatomy 133, 213-25.

SHAWE, G. D. H. (1954) On the number of branches formed by regenerating nerve-fibres. British Journal of Surgery 42, 474-88.

SIMIONESCU, N. \& SIMIONESCU, M. (1976) Galloylglucoses of low molecular weight as mordant for electron microscopy. Journal of Cell Biology 70, 608-21.

SINGER, M. \& STEINBERG, M. C. (1972) Wallerian degeneration, a reevaluation based on transected and colchicine-poisoned nerves in amphibian Triturus. American Journal of Anatomy 133, 51-83.

SOHAL, G. S. \& WEIDMAN, T. A. (1978) Development of the trochlear nerve: Loss of axons during normal ontogeny. Brain Research 142, 455-465.

SOKAL, R. R. \& ROHLF, F. J. (1981) Biometry. San Francisco: Freeman.

SPEIDEL, C. C. (1935) Studies of living nerves. III. Phenomena of nerve irration, recovery, degeneration and repair. Journal of Comparative Neurology 61, 1-82.

SPENCER, P. S. \& THOMAS, P. K. (1974) Ultrastructural studies of the dying-back process II. The sequestration and removal by Schwann cells and oligodendrocytes of organelles from normal and diseased axons. Journal of Neurocytology 3, 763-83.

SPERRY, R. W. (1945) The problem of central nervous reorganization after nerve regeneration and muscle transposition. Quarterly Review of Biology 20, 311-69.

SPERRY, R. W. \& ARORA, H. L. (1965) Selectivity in the regeneration of the oculomotor nerve in the cichlid fish, Astronotus ocellatus. Joumal of Embryology and Experimental Morphology 14, 307-17.

SPRINGER, A. D. (1981) Normal and abnormal retinal projections following the crush of one optic nerve in goldfish (Carassius auratus). Journal of Comparative Neurology 199, 87-95.

STELZNER, D. J. (1982) Regenerating frog optic and mammalian PNS axons. Are they really so different? Trends in Neurosciences 5, 167-9.

STENSAAS, L. J. \& FERINGA, E. R. (1977) Axon regeneration across the site of injury in the optic nerve of the newt Triturus pyrrhogaster. Cell and Tissue Research 179, 501-16.

STEPHENSON, R. S. (1979) Axon reflexes in axolotl limbs: evidence that branched motor axons reinnervate muscles selectively. Experimental Neurology 64, 174-84. 
STERLING, P. (1977) Anatomy and physiology of the goldfish oculomotor system. I. Structure of the abducens nucleus. Journal of Neurophysiology 40, 557-72.

STUERMER, C. A. O. \& EASTER, Jr, S. S. (1984) A comparison of the normal and regenerated retinotectal pathways of goldfish. Journal of Comparative Neurology 223, 57-76.

SUNDERLAND, S. \& BRADLEY, K. C. (1950) Endoneurial tube shrinkage in the distal segment of a severed nerve. Journal of Comparative Neurology 93, 411-20.

THOMAS, P. K. (1963) The connective tissue of peripheral nerve: an electron microscope study. Journal of Anatomy 97, 35-44.

THOMAS, P. K. (1964) Changes in the endoneurial sheaths of peripheral myelinated nerve fibers during Wallerian degeneration. Journal of Anatomy 98, 175-82.

THOMAS, P. K. \& KING, R. H. M. (1974) The degeneration of unmyelinated axons following nerve section: an ultrastructural study. Journal of Neurocytology 3, 497-512.

THOMAS, P. K. \& OLSSON, Y. (1975) Microscopic anatomy and function of the connective tissue components of peripheral nerve. In Peripheral Neuropathy (edited by DYCK, P. J., THOMAS, P. K. \& LAMBERS, E. H.), pp. 168-89. Philadelphia: Saunders.

THOMAS, P. K. \& YOUNG, J. Z. (1949) Internode lengths in the nerve of fishes. Journal of Anatomy $83,336-50$.

TOHYAMA, K., IDE, C., NITATORI, T. \& YOKATA, R. (1983) Nearest neighbor distance of intermediate filaments in axons and Schwann cells. Acta neuropathologica 60, 194-8.

TURNER, J. E. \& SINGER, M. (1974) Ultrastructure of regeneration in the severed newt optic nerve. Journal of Experimental Zoology 190, 249-68.

VARON, S. S. \& BUNGE, R. P. (1978) Trophic mechanisms in the peripheral nervous system. Annual Review of Neuroscience 1, 327-61.

VLODAVSKY, I., LEVI, A., LAX, I., FUKS, Z. \& SCHLESSINGER, J. (1982) Induction of cell attachment and morphological differentiation of a pheochromocytoma cell line and embryonal sensory cells by the extracellular matrix. Developmental Biology 93, 285-300.

WAtrous, W. G. (1940) Axon branching after nerve regeneration. Proceedings of the Society for Experimental Biology and Medicine 44, 541-2.

WEBSTER, H. DE F. (1962) Transient, focal accumulation of axonal mitochondria during the early stages of Wallerian degeneration. Journal of Cell Biology 12, 361-83.

WEBSTER, H. DE F. (1971) The geometry of peripheral myelin sheaths during their formation and growth in rat sciatic nerves. Journal of Cell Biology 48, 348-67.

WEBSTER, H. DE F., MARTIN, J. R. \& O'CONNELL, M. F. (1973) The relationships between interphase Schwann cells and axons before myelination: a quantitative electron microscope study. Developmental Biology 32, 401-16.

WEDDELL, G. (1942) Axonal regeneration in cutaneous nerve plexuses. Journal of Anatomy 77, 49-62.

WEDDELL, G. \& GLEES, P. (1941) The early stages in the degeneration of cutaneous nerve fibres. Journal of Anatomy 76, 65-93.

WEINBERG, H. J. \& SPENCER, P. S. (1976) Studies on the control of myelinogenesis. II. Evidence for neuronal regulation of myelin production. Brain Research 113, 363-78.

WEINBERG, H. J. \& SPENCER, P. S. (1978) The fate of Schwann cells isolated from axonal contact. Journal of Neurocytology 7, 555-69.

WEISS, P. (1934) In vitro experiments on the factors determining the course of the outgrowing nerve fiber. Journal of Experimental Zoology 68, 393-448.

WEISS, P. (1941) Nerve patterns: the mechanics of nerve growth. Growth Supplement 5, 163-203.

WEISS, P. \& CAMPBELL, C. J. (1944) Nerve fiber counts and muscle tension after nerve regeneration in the rat. American Journal of Physiology 140, 616-26.

WEISS, P., EDDS, M. V. \& CAVANAUGH, M. (1945) The effect of terminal connections on the caliber of nerve fibers. Anatomical Record 92, 215-33. 
WEISS, P. \& TAYLOR, A. C. (1944) Further experimental evidence against 'neurotropism' in nerve regeneration. Journal of Experimental Zoology 95, 233-57.

WEISS, P. \& WANG, H. (1945) Transformation of adult Schwann cells into macrophages. Proceedings of the Society for Experimental Biology and Medicine 58, 273-5.

WESTERFIELD, M. \& POWELL, S. (1983) Selective reinnervation of limb muscles by regenerating from motor axons. Developmental Brain Research 10, 301-4.

WETTSTEIN, R. \& SOTELO, J. R. (1963) Electron-microscope study on the regenerative process of peripheral nerves in mice. Zeitschrift für Zellforschung und mikroskopische Anatomie 59, 708-30.

WILliAMS, P. L. \& HALL, S. M. (1972) Chronic Wallerian degeneration: an in vivo and ultrastructural study. Journal of Anatomy 109, 487-503.

WILLiAMS, S. W. (1930) Regeneration of peripheral nerves in Amphibia studied with the aid of a vital stain. Journal of Experimental Zoology 57, 145-81.

YAMADA, K. M., SPOONER, B. S. \& WESSELLS, N. K. (1971) Ultrastructure and function of growth cones and axons of cultured nerve cells. Journal of Cell Biology 49, 614-35.

YU, W-H. A. \& YU, M. C. (1983) Acceleration of regeneration of the crushed hypoglossal nerve by testosterone. Experimenatal Neurology 80, 349-60.

ZELEŃA, J., LUBIŃSKA, L. \& GUTMANN, E. (1968) Accumulation of organelles at the ends of interrupted axons. Zeitschrift für Zellforschung und mikroskopishe Anatomie 91, 200-19. 